\title{
The Insula and Taste Learning
}

\author{
Adonis Yiannakas ${ }^{1}$ and Kobi Rosenblum ${ }^{1,2 *}$ \\ ${ }^{1}$ Sagol Department of Neuroscience, University of Haifa, Haifa, Israel, ${ }^{2}$ Center for Gene Manipulation in the Brain, University \\ of Haifa, Haifa, Israel
}

The sense of taste is a key component of the sensory machinery, enabling the evaluation of both the safety as well as forming associations regarding the nutritional value of ingestible substances. Indicative of the salience of the modality, taste conditioning can be achieved in rodents upon a single pairing of a tastant with a chemical stimulus inducing malaise. This robust associative learning paradigm has been heavily linked with activity within the insular cortex (IC), among other regions, such as the amygdala and medial prefrontal cortex. A number of studies have demonstrated taste memory formation to be dependent on protein synthesis at the IC and to correlate with the induction of signaling cascades involved in synaptic plasticity. Taste learning has been shown to require the differential involvement of dopaminergic GABAergic, glutamatergic, muscarinic neurotransmission across an extended taste learning circuit. The subsequent activation of downstream protein kinases (ERK, CaMKII), transcription factors (CREB, Elk-1) and immediate early genes (c-fos, Arc), has been implicated in the regulation of the different phases of taste learning. This review discusses the relevant neurotransmission, molecular signaling pathways and genetic markers involved in novel and aversive taste

OPEN ACCESS

Edited by:

Hiroyuki Okuno,

Kyoto University, Japan

Reviewed by:

Victor Ramírez-Amaya, Instituto de Investigación Médica Mercedes y Martín Ferreyra (INIMEC),

Argentina

Ranier Gutierrez,

Center for Research and Advanced Studies of the National Polytechnic Institute (CINVESTAV), Mexico

${ }^{*}$ Correspondence: Kobi Rosenblum kobir@psy.haifa.ac.il

Received: 26 June 2017 Accepted: 03 October 2017 Published: 03 November 2017

Citation:

Yiannakas A and Rosenblum K (2017) The Insula and Taste Learning. Front. Mol. Neurosci. 10:335. doi: 10.3389/fnmol.2017.00335 learning, with a particular focus on the IC. Imaging and other studies in humans have implicated the IC in the pathophysiology of a number of cognitive disorders. We conclude that the IC participates in circuit-wide computations that modulate the interception and encoding of sensory information, as well as the formation of subjective internal representations that control the expression of motivated behaviors.

Keywords: insular cortex, insula, taste, taste circuit, ERK-MAPK, translation regulation, immediate early genes

\section{INTRODUCTION}

Traditionally, sensory cortices have been broadly defined and studied in relation to the encoding of stimuli arising from a single sensory modality. The insular cortex (IC) and the orbitofrontal cortex comprise the primary and secondary taste cortices, respectively, being particularly tuned to receive and integrate inputs relating to the modality (Ogawa et al., 1985; Rolls, 1989; Pritchard et al., 1999; Kobayashi, 2006). Cytoarchitectural studies demonstrate the IC to be evolutionarily conserved among mammals, despite considerable structural modification between orders (Butti and Hof, 2010). The struggle for sustenance, combined with the salience of taste in establishing associations regulating behavior, have likely contributed in the evolution of the region, currently viewed by many as a center facilitating encoding, processing, and integration of sensory information (Dosenbach et al., 2007; Seeley et al., 2007).

The anatomical location and the limited responsiveness of the IC under anesthesia have hindered its initial characterization (Reil, 1809). Intraoperative recordings in the 1950s, suggested the IC to function primarily as a visceral sensory region (Penfield and Faulk, 1955; Saper, 1982). 
It was not until the 1980s that single unit recordings during taste information processing were demonstrated, first in rats and later in primates (Yamamoto et al., 1984, 1985; Rolls, 1989; Allen et al., 1991). In more recent fMRI studies in humans, responses of the insula were shown to correlate with the subjective intensity of taste delivered (Grabenhorst and Rolls, 2008; Grabenhorst et al., 2008). Neurological conditions associated with defects in taste perception are rare in humans, but have been observed following IC lesions (Pritchard et al., 1999) or seizures (Isnard et al., 2004). Similarly, in rodents, inactivation of the insula has been associated with significant deficits in a number of taste learning paradigms (Schier et al., 2014, 2016; Blonde et al., 2015; Lin et al., 2015).

Composed of three short gyri, and an additional, ventral accessory gyrus, the anterior insula is home to the gustatory cortex (GC), integral to the representation of tastes, oral texture, and temperature (Shura et al., 2014; Rolls, 2015). On the other hand, the posterior insula, composed of two elongated gyri, is primarily involved in autonomic, sensorimotor and nociceptive processing (Craig, 1996; Brooks et al., 2005; Shura et al., 2014). The lobe is further subdivided in the dorso-ventral cytoarchitectural plane, namely granular (gIC), dysgranular (dIC), and agranular layers (aIC) that relate to progressive changes in the laminar organization of the cortex (Penfield and Rasmussen, 1950; Penfield and Faulk, 1955).

In both humans and rodents, taste perception begins in the periphery, with central axons of cranial nerve ganglia relaying information from taste cells within taste buds of the tongue (and oral cavity). Distinct subclasses of taste receptor cells are known to regulate the perception of salty, sweet, sour, bitter and umami taste in rodents (Mueller et al., 2005; Huang et al., 2006; Chandrashekar et al., 2010; Yarmolinsky et al., 2014). Taste information is conveyed to the rostral and lateral nucleus tractus solitaris of the medulla (Carleton et al., 2010). In rodents, unlike primates, where the PBN is by-passed, fibers from the rostral nucleus tractus solitaris (rNTS) project to the parabranchial nucleus (PBN) and subsequently to the ventroposteromedial nucleus of the thalamus (VPMpc). Rodent gustatory fibers in the PBN projecting to the gustatory thalamus terminate in the IC, laterally and adjacent to the olfactory bulb (Carleton et al., 2010). The rodent and primate insula receives main afferents from the basolateral amygdala (BLA), the dorsal thalamus, other sensory cortical regions, but also the lateral hypothalamus (LHA), the ventral tegmental area (VTA), substantia nigra and dorsal raphe nucleus (Mesulam and Mufson, 1982a,b; Allen et al., 1991). Most of these afferents terminate in the posterior gIC, whereas the ventral aIC predominantly receives limbic input.

Chemosensory information, is encoded through time-varying changes in neuronal firing rates of populations of neurons of the GC (Katz et al., 2001, 2002). States of partially coordinated activity last from few to hundreds of milliseconds and suddenly end, transitioning to the next state (Jones et al., 2007). Activation of the insula has been observed within $200 \mathrm{~ms}$ of licking a tastant in rodents (Gutiérrez et al., 2010), while taste discrimination occurs within the $400 \mathrm{~ms}$ range (Perez et al., 2013). Electrophysiological recordings from GC neurons in rats during intraoral tastant delivery, have further demonstrated this activity to extend up to $2.5 \mathrm{~s}$ from licking, incorporating palatability signals relating to the tastant (Sadacca et al., 2012).

In vivo electrophysiological recordings in rats have demonstrated neuronal ensembles to respond to all, some or none of the four basic taste qualities (Jones et al., 2007). This view was supported by findings using intrinsic in vivo imaging (Accolla et al., 2007), demonstrating spatial segregation of the neural ensembles representing different taste modalities, but no distinct sub-regional segregation. Nonetheless, two tastants of similar hedonic value activated areas in common regions more often than two tastants with opposite hedonic value, likely facilitating discrimination (Accolla et al., 2007). GC spatiotemporal activity patterns have thus been implicated in the encoding of palatability and/or aversiveness of taste (Accolla and Carleton, 2008), even though the precise sources of valence-related information is still debatable. Reciprocal connections of the GC with the amygdalar complex in particular, have been heavily implicated in reward-related encoding (Stone et al., 2011; Jezzini et al., 2013; Haley et al., 2016).

Studies in mice on the other hand, have argued for a spatially hardwired role of insular sub-regions, shaping a gustotopic map of taste qualities (Chen et al., 2011; Peng et al., 2015). Within this gustotopic map, each taste quality is thought to be encoded by distinct cortical fields, whose activation elicits hardwired behavioral responses. Optogenetic activation of brain fields representing sweet or bitter taste at the GC were shown to exert opposing effects in tests of place preference, leading to aversion to the bitter-associated context. Furthermore, stimulated activation of these GC ensembles, overcame orally generated signals of opposing valence, in go/no go drinking tasks (Peng et al., 2015).

This discrepancy could relate to non-specific activation of regions that participate in the encoding of hedonic value or autonomic-visceral output (Accolla et al., 2007; Accolla and Carleton, 2008). Mice lacking receptors for sweet taste (TRP5-/-), still develop a preference for sucrose over water, demonstrating taste preference to be modulated by non-gustatory inputs such as visceral information and caloric content (de Araujo et al., 2008). Indeed, lesion studies in rats have argued aversive taste memories to be most severely disrupted following damage to the posterior GC overlapping with the visceral cortex, than lesions of the GC alone (Schier et al., 2014, 2016).

Earlier in vivo imaging studies of intrinsic neuronal activity of the rat GC, demonstrated differential spatial patterns of activation in response to appetitive saccharin and innately aversive quinine (Accolla and Carleton, 2008). However, in animals trained to be averse to saccharin, internal representations exhibited plasticity, resembling quinine responses (Accolla and Carleton, 2008). Further plasticity (to a saccharin-like pattern) was induced by behavioral extinction of saccharin aversion, underlining that GC activity maps are influenced by associated internal states and hedonics (Carleton et al., 2010). In further support, latest studies utilizing anterograde tracers and twophoton imaging, have noted no apparent spatial organization of primary taste qualities in the layers $2 / 3$ of the GC, just posterior to the middle cerebral artery, in male and female mice (Fletcher et al., 2017). Interestingly, neuronal firing at the GC was shown to participate in the encoding of auditory cues predicting tastants, 
which following learning were sufficient to evoke a gustatory response even when fluid delivery was omitted (Gardner and Fontanini, 2014). Such cue responses are not commonly observed in sensory cortices, and likely underlie the ability of tastants to act as rewards themselves (Samuelsen et al., 2012, 2013).

Thus, despite its prominent role in the sense of taste, in both primates and other mammals, GC activity can be modulated by cross-modal stimuli (Ghazanfar and Schroeder, 2006; Driver and Noesselt, 2009). The multimodality of IC responses, is not necessarily due to the order of taste sensation in relation to other sensory stimuli, as this can be argued for all perceived sensory stimuli (Zhou and Fuster, 2000; de Araujo and Simon, 2009; Vincis and Fontanini, 2016). Out with physiochemical and affective dimensions of taste, single neuron recordings from neurons of the IC encode tactile, thermal and olfactory information from the oral cavity (Yamamoto et al., 1981; Stapleton et al., 2006; Spence, 2015). The rodent and human rostral agranular insula and its connections has also been implicated in sensorimotor and nociceptive processing, as well as pain inhibitory control (Krushel and van der Kooy, 1988; Craig, 2003; Jasmin et al., 2004; Gogolla et al., 2014; Qiu et al., 2014). Studies of the IC in humans in the past 2 decades, have further implicated the region in interoceptive awareness and the formation of subjective internal representations of experiences and feelings guiding cognition and behavior (Damasio, 2003). This proposed role could relate to the ability of the IC to form internal representations of bodily reactions during sensory experiences (Craig, 2002, 2009; Critchley et al., 2005; Kurth, 2010).

Nevertheless, IC lesions do not disrupt feelings, sentience, or the ability to form taste associations, as the cortex is not the only source and processor of information relating to sensory experiences or inner experiences (Philippi et al., 2012; Damasio et al., 2013). Indeed neural substrates for feeling states initially formed subcortically are sufficient for retrieval, despite their long-term storage in the cortex (Cahill and MacGaugh, 1996). The IC could thus be viewed as a hub of integration of information regarding sensory perception, hedonic and novelty aspects of experiences, with bodily information to facilitate decision making and abstract though (Pritchard et al., 1999; Craig et al., 2000; Bushara et al., 2001, 2003; Baliki et al., 2009; Ibanez et al., 2010).

Single unit recordings and analysis of immediate early gene expression, demonstrated cross-modal responses to be present before learning at the GC and to increase in prevalence and specificity following stimulus-taste associations (Saddoris et al., 2009). Integration of sensory and reward stimuli at the IC, is made possible through interactions with the limbic system, the thalamus and the amygdalar complex in particular (Piette et al., 2012; Samuelsen et al., 2013). In humans and rodents, the BLA is understood to respond strongly to pleasant or unpleasant gustatory stimuli specifically, encoding their relative salience (Small et al., 2003; Fontanini et al., 2009). Palatability related inputs at the IC are abolished in response to BLA lesions (Piette et al., 2012), while during novel taste exposure, changes in ICBLA connectivity shape the valence of the association (Grossman et al., 2008; Stone et al., 2011). The IC-BLA circuit is increasingly implicated in the formation of taste aversions, however, data at this stage remains largely correlative.

A particular gap in the literature appears to be the precise role of GC and its connectivity with other cortical or lower brain regions during the acquisition of familiarity to appetitive tastants (Lin and Reilly, 2012; Lin et al., 2015). Studies aiming to fully examine the causative role of correlative changes in the expression of genes and protein associated with activity and structural plasticity will hopefully shed more light in the neural and molecular mechanisms of novel taste learning (Koh et al., 2003; Doron and Rosenblum, 2010; Bermudez-Rattoni, 2014).

Insights into molecular and neuroanatomical mechanisms through which the insula is able to encode sensory inputs and serve its complex function stem primarily from basic science studies focusing on taste learning (Bermudez-Rattoni and McGaugh, 1991; Rosenblum et al., 1993; Katz and Harris-Warrick, 1999). Understanding the precise neurobiology involved, holds the potential of revealing how the brain is able to encode, consolidate, and evoke salient information, and thereby coordinate behavior. The focus of this review is to describe the molecular and cellular activity evoked in the insula during encoding or retrieval of hedonic, novelty- and internal body state-related taste-learning inputs.

\section{TASTE LEARNING BEHAVIORS}

Associative learning paradigms such as classical conditioning demonstrate the evolutionary crucial ability of animals to link stimulus and outcome, steering behavior toward positive experiences, instinctively or through learning (Darwin, 1859; James, 1884; Pavlov, 1927; Zajonc, 1980). Unlike other associative learning paradigms, taste conditioning can be achieved in rodents upon a single pairing of a tastant (e.g., 0.5\% saccharin water) to a moderate dose of a malaise-inducing agent, e.g., $\mathrm{LiCl}$ (Nachman, 1970). Consumption of the conditioned stimulus (CS-e.g., saccharin) is associated with the aversive consequences of the unconditioned stimulus (US-e.g., LiCl), resulting in conditioned taste aversion (CTA) acquisition (Bures et al., 1998; Rosenblum, 2008). Rodents, like all mammals, are naturally hesitant to consume a novel taste due to lack of knowledge regarding its post-ingestive consequences, a phenomenon described as taste neophobia (Barnett, 1958; Carroll et al., 1975). Novel stimuli are typically consumed at limited quantities compared to familiar ones, allowing for examination of postingestive consequences (Buresova, 1978; Buresova and Bures, 1980). Following familiarization, if tastants are deemed as safe, neophobia is attenuated and consumption increases (Bures et al., 1998). A number of studies have heavily implicated the insula in the encoding and familiarization to novel tastants as well as the acquisition, retention and extinction of aversive taste memories (Bermudez-Rattoni, 2004, 2014; Rosenblum, 2008; Gal-Ben-Ari and Rosenblum, 2012).

Aversion to bitter substances such as quinine and phenylthiocarbamide is unconditionally induced upon encounter through innate hereditary mechanisms in the natural setting (Kutscher and Wright, 1977; Kutscher et al., 1977; Whitney and Harder, 1986). Bitter tastes are naturally 
avoided, while sweet tastes are preferred (Spector, 2015). Characteristically, quinine hydrochloride, commonly used as a bitter tastant experimentally, represents a measure of taste aversion, generally thought not to be generated through learning (Zhang et al., 2003; Yamamoto, 2006, 2008). Studies in rats indicate that extensive lesions of the GC in rats leave quinine and sucrose responses unaffected, unlike pre-surgically acquired CTA to $\mathrm{NaCl}$ (Kiefer and Orr, 1992). Although follow-up studies have indicated that lesions of $91 \%$ of the GC also affect behavioral responses to quinine (Bales et al., 2015), it is likely that these results relate to disruption of cells between the taste and visceral area, that receive convergent baroreceptor, chemoreceptor, gustatory and nociceptive inputs (Hashimoto and Spector, 2014). Evidence suggests that regions play a more prominent role in the regulation of innate taste avoidance behavior, such the ventral striatum, the nucleus accumbens (Yamamoto, 2006, 2008; Rotella et al., 2015) and the balance of inputs to the lateral hypothalamus from the parabranchial nucleus and CeA (Riley and King, 2013; Tokita et al., 2014).

CTA acquired in neophobic animals is a more robust conditioned response (CR), in contrast to CTA to familiar tastants (Garcia et al., 1966) where the animal has to modify the existing safe taste memory trace into one associated with malaise (Pavlov, 1927; Lubow, 1973). This behavioral response is defined as latent inhibition of CTA and is thought to involve re-learning rather than erasing of existing memories (De la Casa and Lubow, 1995; Naor and Dudai, 1996). Latent inhibition (LI) has been produced with different classical and instrumental conditioning paradigms (Lubow, 1989). It was first suggested to arise because of reduced salience of the stimulus as a result of past experience in non-reinforced pre-exposures (MacKintosh, 1975). However, LI most closely compares with habituation where a decline in the attentional orienting response, a measure of stimulus associability (Pearce and Hall, 1980; Swan and Pearce, 1988), is observed within and between sessions of stimulus presentation (Hall and Pearce, 1979; Kaye and Pearce, 1987). The associability of a stimulus declines as its associative strength increases (Pearce and Hall, 1980; Swan and Pearce, 1988) while the orienting response to the CS declines as associative strength increases through training (Kaye and Pearce, 1984). Despite their similarities, habituation and LI are differentially affected by changes in intrinsic salience (Hall, 1991) and context change (Hall and Channell, 1985; Rudy and O'Reilly, 1999).

CTA learning is susceptible to extinction (CTAE) over time following repeated unreinforced CS exposures (Buresova and Bures, 1979). Following Extinction, CTA can be reinstated by administration of the US, context change (Rosas and Bouton, 1997) or spontaneously over time, depending on US strength (Rosas and Bouton, 1998). Extinction is a fundamental topic in investigating experimental psychology of learning and learning theory (Pavlov, 1927; Rescorla and Wagner, 1972; Mackintosh, 1983; Bouton, 1994). Experimental extinction does not involve deleting of the original trace, rather relearning in which memories of unreinforced exposures to the CS, dictate expectation and behavior. This view is supported by a number of findings: (a) spontaneous recovery-once extinguished, CRs may partly recover with time without further training (Pavlov, 1927;
Brooks et al., 1999), (b) saving-reacquisition of extinguished behavior can be achieved in fewer trials than naive training (Ebbinghaus, 1964), (c) reinstatement-US exposure alone may restore the CR regardless of the time (Rescorla and Heth, 1975) and (d) renewal-switching out of the extinction context causes CR to reemergence (Bouton and Swarzentruber, 1991).

Research in CTAE is expected to contribute to our understanding of brain processes and mechanisms which interact to determine the dominant characters of internal representations modulating behavior. Once acquired emotional associations are not always expressed, yet regulation of emotional expression under varying environmental conditions is essential for mental health (Quirk and Mueller, 2008). Furthermore, this research could contribute to delineating process through which specific aversive, pleasant or emotional memories are consolidated or modified, providing cues as to how individual memory components can be manipulated to treat disease. Even though studies of the mechanisms underlying the extinction and reinstatement of taste aversion memories are still in their early stages, evidence from human patients highlight the process to involve multisensorial encoding and likely the formation of associations with internal states over periods of time (Berlucchi et al., 2004; Brozzoli et al., 2006). As mentioned, studies have implicated molecular signaling cascades and structural plasticity at the IC of rodents (as well as the medial Pre-frontal Cortex (mPFC), Amygdala and Periaqueductal Gray) in the expression of extinction behavior and potential mechanisms of reinstatement (Berman et al., 2003; Mickley et al., 2005, 2011; Accolla and Carleton, 2008; Maroun et al., 2012; Slouzkey et al., 2013). Of particular interest from our point of view, would be how changes in activity or plasticity within distinct components of the taste-learning circuit, for example how the IC-BLA or mPFC-BLA circuits influence the dominance or extinction of specific engrams (Joels and Lamprecht, 2014; Rodriguez-Duran et al., 2017).

\section{SYNAPTIC PLASTICITY AND TASTE LEARNING}

Studies of the role of the insula in taste learning are increasingly revealing of circuit-wide mechanisms through which the brain coordinates continuous processing and updating of relevant sensory information integrating cognition and behavior (Dudai and Eisenberg, 2004; Fontanini et al., 2009; Senn et al., 2014). During memory acquisition, internal representations of novel information are formed at the cellular and molecular level (Muller and Pilzecker, 1900). Information encoded during acquisition remains labile for a period of time allowing for memory consolidation. Consolidation allows the original memory to transform from short- to long-term memory (McGaugh, 2000; Kandel, 2001; Dudai and Eisenberg, 2004). Memory reconsolidation following memory retrieval will once again render the memory engram labile to metaplastic events in relation to the retrieval setting (Bailey et al., 2004). The consolidation of memory can indeed be disrupted by a number of events such as new learning itself, brain cooling, seizures, trauma, 
and regional lesions (Alberini, 2011). Importantly, studies using treatments disrupting specific cellular processes such as de novo RNA or protein synthesis, as well as the expression or function of specific proteins within the insula, have been successful in modulating taste memory consolidation (Rosenblum et al., 1993; Bures et al., 1998; Merhav and Rosenblum, 2006).

Long-term potentiation (LTP) and its reciprocal long-term depression (LTD) represent the most common cellular model for learning and memory (Bliss and Lomo, 1973). Tetanic stimulation of the BLA prior to training promotes LTP in the IC, and enhances CTA memory retention, demonstrating that synaptic plasticity mechanisms could provide the cellular basis for circuit-wide adaptations to learning (Escobar and BermudezRattoni, 2000). In further support, microinfusion of the known modulator of synaptic plasticity (Braham and Messaoudi, 2005), brain-derived neurotrophic factor (BDNF) into the IC, was associated with the induction of LTP in the BLA-IC projection (Escobar et al., 2003), improving CTA consolidation (Castillo et al., 2006). Importantly, IC-LTP and CTA memory exhibit shared molecular mechanisms in the IC, such as NMDAR dependence, activation of ERK1/2, and induction of immediate early genes (IEGs), including Zif268, Fos, Arc, and Homer (Jones et al., 1999; Rodriguez-Duran and Escobar, 2014).

Another mechanism shared by late phase LTP and long term memory is the requirement for transcription and translation (Davis and Squire, 1984; Pittenger et al., 2000; Costa-Mattioli et al., 2005; Kandel, 2012). In the case of taste memory, regulation of transcription and translation occurs in the IC, altering synaptic efficacy and strength (Jones et al., 1999; Jones and Katz, 2006; Rodriguez-Duran et al., 2011). Signaling pathways that promote plasticity-related changes in protein expression promote the activation of transcription factors, regulating IEGs, such as Arc and c-fos (Guzowski et al., 1999; Yasoshima et al., 2006a,b; Mickley et al., 2007; Okuno, 2011). The relative expression of IEGs is widely used to discriminate active neurons following learning and memory, and provides an important link between stimulus-dependent changes in neuronal circuit activity and intracellular molecular mechanisms (Melzer and Steiner, 1997).

Phosphorylated CREB promotes the transcription of a number of genes involved in synaptic plasticity including Arc, $B d n f, c-f o s, z i f 268$, as well as CCAAT/enhancer binding protein $(C / E B P \beta)$ (Sheng et al., 1990; Finkbeiner et al., 1997; Ying et al., 2002; Ma et al., 2011). CREB phosphorylation in the IC is increased following administration of LiCl or CTA, but not in response to novel taste learning (Swank, 2000; Desmedt et al., 2003). Following novel taste learning, an early shared response in the rodent brain includes the phosphorylation of activity and plasticity marker ERK MAPK in the insular cortex and hippocampus, specifically (Yefet et al., 2006). Conversely, CREB and Akt are phosphorylated in the hippocampus and the cortex during aversive taste memory consolidation, but not during novel taste learning (Swank, 2000; Desmedt et al., 2003; Yefet et al., 2006).

Neurotransmission at the IC underlies the appearance of short- and long-term memory traces that correlate with the strength of associative learning, and shape subsequent behavioral responses to the now-familiar tastant (Doron and
Rosenblum, 2010; Yamamoto et al., 2010; Adaikkan and Rosenblum, 2015). Nonetheless, taste learning is subserved by an extended integrative circuit. The IC is bidirectionally linked with the parvocellular portion of the ventroposteromedial thalamic nucleus (VPMpc), as well as the Central and Basolateral Amygdala (CeA and BLA), receiving and processing visceral and emotional information (Koh et al., 2003; BermudezRattoni, 2004; Ferreira et al., 2005; Rosenblum, 2008; Lin and Reilly, 2012). More recent studies have suggested myosin II to regulate actin-related rearrangements in synaptic structure at the Infralimbic mPFC during CTAE (Bi et al., 2015). Further studies specific influence of such events on neurotransmission at the IC or indeed the extended taste during the different phases of taste learning would be particularly interesting.

Anatomical and other functional evidence have highlighted the importance of the IC-BLA interactions CTA learning (Miller et al., 1986; Bermudez-Rattoni and McGaugh, 1991; Bielavaska and Roldan, 1996; Reilly and Trifunovic, 2001; Guzman-Ramos and Bermudez-Rattoni, 2012). Lesions of both the IC and BLA (but not the CeA) have been shown to produce stronger impairments in CTA acquisition than when done separately (Gallo et al., 1992; Bielavaska and Roldan, 1996; Miranda and McGaugh, 2004). Furthermore, cellular compartmental analysis of temporal gene transcription by fluorescence in situ hybridization (catFISH) in rats, indicated that at the IC and BLA, CS- and US-information encoding is associated with increases in cytoplasmic and nuclear Arc mRNA respectively (Barot et al., 2008). Interestingly, convergent encoding of the two stimuli was only observed in sub-populations of neurons of the BLA but not the agranular IC upon CS-US pairing (Barot et al., 2008). As Barot et al. suggested, CS novelty is likely to be instrumental in potentiating both subsequent US neuronal activation, as well as the formation of an association through timely changes in Arc mRNA expression and localization at BLA neurons. However, findings from this study also indicated CS-specific increases in cytoplasmic (but not nuclear) Arc mRNA at the dysgranular IC, independent of conditioning (Barot et al., 2008). It is thus likely that even though coincidence detection using catFISH in this study was a valid means of CS-US association encoding at the BLA, it did not necessarily encapsulate the spatiotemporal IEG induction pattern employed at the IC during CS-US associations, which can manifest independently of the amygdala (Saddoris et al., 2009). Furthermore, such coincidence detection might indeed take place at a different time point at the IC, as part of the elegantly demonstrated NMDAR-CAMKII-AMPAR-dependent short-term memory trace, required for CS-US association and effective CTA memory formation (Adaikkan and Rosenblum, 2015).

Thus, the two regions do not serve the same function, but are distinct components of the circuit subserving the different phases of taste memory formation and consolidation through plasticity and complex connectivity (Grossman et al., 2008; Kim et al., 2010; Chen et al., 2011). In the subsequent sections we summarize current findings regarding neurotransmitter systems and molecular signaling cascades implicated in the encoding of novel, and aversive taste memories in the IC, 
and the extended neuronal circuit facilitating their persistence. The final section of the manuscript is devoted to the role of IEG induction at the IC during the novel and aversive taste learning, and how these facilitate memory formation and persistence.

\section{NOVEL TASTE MEMORY ENCODING AND THE INSULA}

Taste information is transferred from the oral cavity to the cortex by the main excitatory neurotransmitter of the mammalian brain, glutamate (Rosenblum, 2008; Rondard et al., 2011). Glutamatergic pathways modulate novelty-driven increases in cortical cholinergic activity, mediated by cholinergic projections of the nucleus basalis magnocellularis (NBM) (Rasmusson, 1993; Giovannini et al., 1995; Moor et al., 1998). Lesion-induced damage to the NBM and its projections to the cortex were previously associated with impairments in the performance of operant spatial memory tasks, working memory, novelty encoding, as well as locomotor activity in rats (Dunnet et al., 1991; Dunnet, 1993; Everitt and Robbins, 1997; Sarter and Bruno, 1997; Himmelheber et al., 2001; Pepeu and Giovannini, 2004).

Cholinergic deafferentation of the cortex in combination with the muscarinic antagonist scopolamine in rats disrupted CTA memory acquisition similarly to excitotoxic lesions (Gutiérrez et al., 1999b,c). In another study, in vivo microdialysis was utilized to measure extracellular levels of acetylcholine (ACh) in rats, demonstrating that $\mathrm{ACh}$ release in the IC increases in response to novel taste presentation and decreases with each subsequent encounter, finally reaching levels observed during water presentation (Miranda and Bermudez-Rattoni, 1999; Miranda et al., 2000). In studies where the NBM afferents to the IC were inactivated prior to taste presentation, ACh release in the IC was inhibited and novel taste learning was impaired (Miranda and Bermudez-Rattoni, 1999; Miranda et al., 2000). Cellular mechanisms downstream of ACh are key in allowing new learning to take place at the cortex. The release and detection of ACh promotes (a) the enhancement of afferent inputs relative to excitatory feedback, (b) persistent spiking required for active maintenance, as well as (c) synaptic modification, (d) while regulating inhibition and $\theta$ oscillations (Hasselmo and McGaughy, 2004; Hasselmo and Giocomo, 2006).

ACh produces biphasic changes in the activity of excitatory neocortical neurons, comprised of fast inhibition, followed by slow, potassium channel dependent depolarization of pyramidal cells (McCormick and Prince, 1985, 1986; Delmas and Brown, 2005). Fast inhibition is mediated by both nicotinic (nAChRs) and muscarinic ( $\mathrm{mAChRs}$ ) receptors that increase the excitability and firing rates of dendrite-targeting GABAergic interneurons (Kawaguchi and Kubota, 1997; Ferezou et al., 2002; Couey et al., 2007; Gulledge et al., 2007; Fanselow et al., 2008; Arroyo et al., 2012). Interestingly, the suppressive effect of novelty-specific $\mathrm{mAChR}$ activation is limited to excitation of intracortical intrinsic afferents, but does not affect those evoked by thalamocortical afferents, maintaining the cortex in a state of receptiveness (Gil et al., 1997; Kimura et al., 1999; Kimura, 2000).

Inhibitory neurotransmission by GABA, modulates noveltydriven cholinergic activity in the IC through inhibition within cortical interneuron networks in concert with NBM inputs (Wood and Richard, 1982; Zaborsky et al., 1986) or through GABAA receptor activation in the NBM alone (Chu et al., 1990; DeSousa et al., 1994). Electrophysiological studies demonstrated GABAergic modulation and screening of taste information at both the oral cavity as well as the IC (Ogawa et al., 1998). The infusion of GABA or the $\mathrm{GABA}_{\mathrm{A}}$ receptor agonist muscimol into the NBM results in decreased cortical ACh release (Casamenti et al., 1986), and impairs performance in several paradigms (Majchrzak et al., 1990; Dudchenko and Sarter, 1991; Muir et al., 1992; Pepeu and Giovannini, 2004). This crucial interplay between ACh and GABA neurotransmission in the IC has only recently been comprehensively addressed with regards to taste novelty (Rodriguez-Garcia and Miranda, 2016). Administration of bicuculline, a $\mathrm{GABA}_{\mathrm{A}}$ receptor antagonist into the IC or the NBM $24 \mathrm{~h}$. prior to novel taste presentation in rats, was of no consequence to the behavioral response or to $\mathrm{ACh}$ release. This treatment was nonetheless sufficient to inhibit the physiological suppression of $\mathrm{ACh}$ release required for the acquisition of taste familiarity, and inhibited the physiological attenuation of neophobia (AN) (Rodriguez-Garcia and Miranda, 2016).

In addition, there is an interplay between $\mathrm{ACh}$, gammaaminobutyric acid (GABA), and glutamate in the IC, as administration of the muscarinic agonist carbachol into the IC increases the amplitude of unitary inhibitory post-synaptic currents (uIPSCs) within local interneuron networks, but suppresses uIPSCs in local pyramidal cells (Yamamoto et al., 2010). This ACh-GABA-glutamate interplay in the IC is thought to occur by novelty-driven cholinergic activation that exerts cell-type specific effects on neuronal excitation by manipulating GABA release into interneuron synapses, modulating the excitatory output in the IC (Fujita et al., 2010). Table 1 summarizes the involvement of different neurotransmitter systems in taste learning behaviors.

Novelty-driven cholinergic neurotransmission in the cortex is primarily dependent on mAChRs that utilize $G$ proteins as their signaling mechanism (Clarke, 1993). Activation of mAChRs in the IC during the acquisition of novel taste memory acts upstream of protein synthesis and plasticity stimulating pathways (Rosenblum et al., 2000; Rodriguez-Garcia and Miranda, 2016; Rosenberg et al., 2016b). One of these is the mitogen-activated protein kinase (MAPK) pathway, a key regulator of protein synthesis, is a crucial signal transduction cascade in synaptic plasticity and memory consolidation, modulating both early and late phases of learning-associated LTP and LTD (Sweatt, 2001; Rosenblum et al., 2002; Thiels et al., 2002). In addition to translation, ERK/MAPK is one of the kinase signaling cascades that are regulated by second messengers, and in turn regulate a wave of transcriptional activity in response to neuronal stimulation (Thomas and Huganir, 2004; Bluthgen and Legewie, 2008).

Phosphorylation-dependent activation of the extracellular receptor kinase (ERK 1/2) downstream of MAPK/ERK kinase 
(MEK) is known to alter the translation of mRNA to protein through phosphorylation of the 40S ribosomal protein S6 kinase (RSK) and subsequent activation of ribosomal protein S6 (Pende et al., 2004). In addition, a number of activity-regulated genes have been reported to be dependent upon ERK phosphorylation through direct or indirect interactions with transcription factors such as ELK-1 and CREB (Thomas and Huganir, 2004; Davis and Laroche, 2006).

TABLE 1 | Neurotransmission at the IC modulated by Taste Learning.

\begin{tabular}{|c|c|c|c|}
\hline $\begin{array}{l}\text { Learning } \\
\text { paradigm }\end{array}$ & Manipulation & Effect & References \\
\hline \multirow{7}{*}{$\begin{array}{l}\text { Novel Taste } \\
\text { Learning }\end{array}$} & mAChR antagonism & $\downarrow$ & Berman et al., 1998 \\
\hline & mAChR antagonism & $\downarrow$ & $\begin{array}{l}\text { Rodriguez-Garcia and } \\
\text { Miranda, } 2016\end{array}$ \\
\hline & GABA(A) antagonism & - & $\begin{array}{l}\text { Rodriguez-Garcia and } \\
\text { Miranda, } 2016\end{array}$ \\
\hline & GABA(B) antagonism & $\downarrow$ & Wu et al., 2017 \\
\hline & NMDAR NR2B inhibition & $\downarrow$ & $\begin{array}{l}\text { Barki-Harrington et al., } \\
2009\end{array}$ \\
\hline & NMDAR antagonism & - & Gutiérrez et al., 2003a \\
\hline & NMDAR antagonism & - & $\begin{array}{l}\text { Rosenberg et al., } \\
2016 a\end{array}$ \\
\hline
\end{tabular}

\begin{tabular}{lll}
\hline $\begin{array}{l}\text { Attenuation of } \\
\text { Neophobia }\end{array}$ & $\downarrow$ & David et al., 2014 \\
Glutamate & $\downarrow$ & $\begin{array}{l}\text { Ramirez-Lugo et al., } \\
\text { mGLUR1 antagonism }\end{array}$ \\
& $\uparrow$ & $\begin{array}{l}2015 \\
\text { Ramirez-Lugo et al., } \\
\end{array}$ \\
& & 2015
\end{tabular}

\begin{tabular}{|c|c|c|c|}
\hline \multirow{7}{*}{$\begin{array}{l}\text { Latent } \\
\text { Inhibition }\end{array}$} & AMPAR antagonism & $\downarrow$ & Berman et al., 2000 \\
\hline & D1/D5 antagonism & $\downarrow$ & Berman et al., 2000 \\
\hline & GABA(A) antagonism & $\downarrow$ & Berman et al., 2000 \\
\hline & mAChR antagonism & $\downarrow$ & Berman et al., 2000 \\
\hline & mGLUR2/3 antagonism & $\downarrow$ & Berman et al., 2000 \\
\hline & NMDAR antagonism & $\downarrow$ & Berman et al., 2000 \\
\hline & $\beta$-Adrenoreceptor antagonism & $\downarrow$ & Berman et al., 2000 \\
\hline \multirow{9}{*}{$\begin{array}{l}\text { CTA } \\
\text { Acquisition }\end{array}$} & AMPAR antagonism & $\downarrow$ & Berman et al., 2000 \\
\hline & D1/D5 antagonism & $\downarrow$ & Berman et al., 2000 \\
\hline & GABA(A) antagonism & $\downarrow$ & Berman et al., 2000 \\
\hline & mAChR antagonism & $\downarrow$ & Berman et al., 2000 \\
\hline & mGLUR2/3 antagonism & $\downarrow$ & Berman et al., 2000 \\
\hline & NMDAR antagonism & $\downarrow$ & Berman et al., 2000 \\
\hline & $\beta$-Adrenoreceptor antagonism & $\downarrow$ & Berman et al., 2000 \\
\hline & GABA(B)1b KO mice & $\downarrow$ & Jacobson et al., 2006 \\
\hline & GABA(B)1b KO mice & No CTAE & Jacobson et al., 2006 \\
\hline \multirow[t]{2}{*}{$\begin{array}{l}\text { CTA } \\
\text { Consolidation }\end{array}$} & Glutamate & $\uparrow$ & $\begin{array}{l}\text { Guzman-Ramos et al., } \\
2010\end{array}$ \\
\hline & Dopamine & $\uparrow$ & $\begin{array}{l}\text { Guzman-Ramos et al., } \\
2012\end{array}$ \\
\hline \multirow[t]{2}{*}{ CTA Retrieval } & AMPAR antagonism & $\downarrow$ & Berman et al., 2000 \\
\hline & GABA(A) agonism & $\downarrow$ & Berman et al., 2000 \\
\hline
\end{tabular}

ERK phosphorylation is required for the physical manifestation of learning at activated synapses, and serves as a hub of plasticity-related neurotransmission (Berman et al., 1998, 2000). mAChR-dependent activation of ERK in the IC during novel taste learning (Berman et al., 1998; Belelovsky et al., 2005) is not accompanied by activation of other related kinases (Rosenblum et al., 2000), and is necessary for IC LTP induction in this context (Jones et al., 1999). ERK activation following taste learning is both time- and region-specific, in that it is observed in the IC 20 min after taste learning, but not necessarily in other memory-related regions (Berman et al., 1998; Swank and Sweatt, 2001; Sweatt, 2001; Yefet et al., 2006). Studies using the muscarinic agonist carbachol have demonstrated this effect to be Src-dependent and partially phosphoinositide-3 kinase $(\mathrm{PI} 3-\mathrm{K})$ - and $\mathrm{Ca}^{2+}$-dependent, but protein kinase $\mathrm{C}$ (PKC)-independent (Kim et al., 1999; Rosenblum et al., 2000; Budd et al., 2001). Nonetheless, taste memory formation and stabilization in the IC is subject to perturbation by multiple neurotransmitter systems (Table 2).

The balance of GABAergic activation within the IC regulates the ability of organisms to attribute salience and encode information regarding sensory stimuli during memory

TABLE 2 | Intracellular Signaling at the IC modulated by the Taste Learning.

\begin{tabular}{|c|c|c|c|c|}
\hline $\begin{array}{l}\text { Learning } \\
\text { paradigm }\end{array}$ & $\begin{array}{l}\text { Signaling } \\
\text { molecule }\end{array}$ & $\begin{array}{l}\text { Phosphorylation } \\
\text { site }\end{array}$ & Effect & References \\
\hline \multirow{13}{*}{$\begin{array}{l}\text { Novel Taste } \\
\text { Learning }\end{array}$} & eEF2 & T56 & $\uparrow$ & Belelovsky et al., 2005 \\
\hline & ELKI & S383 & $\uparrow$ & Berman et al., 1998 \\
\hline & ERK & T202/Y204 & $\uparrow$ & Berman et al., 1998 \\
\hline & ERK & T202/Y205 & $\uparrow$ & $\begin{array}{l}\text { Swank and Sweatt, } \\
2001\end{array}$ \\
\hline & JNK I/II & T183/Y185 & $\uparrow$ & Berman et al., 1998 \\
\hline & MEK & S217/221 & $\uparrow$ & $\begin{array}{l}\text { Swank and Sweatt, } \\
2001\end{array}$ \\
\hline & mTOR & Ser2448 & $\uparrow$ & Belelovsky et al., 2009 \\
\hline & NMDAR NR2B & Y1472 & $\uparrow$ & $\begin{array}{l}\text { Nunez-Jaramillo et al., } \\
2008\end{array}$ \\
\hline & NMDAR NR2B & Y1473 & $\uparrow$ & $\begin{array}{l}\text { Barki-Harrington et al., } \\
2009\end{array}$ \\
\hline & p90RSK & S381 & $\uparrow$ & $\begin{array}{l}\text { Swank and Sweatt, } \\
2001\end{array}$ \\
\hline & PSD-95 & & $\uparrow$ & Elkobi et al., 2008 \\
\hline & Raf & S259 & $\uparrow$ & $\begin{array}{l}\text { Swank and Sweatt, } \\
2001\end{array}$ \\
\hline & S6K1 & Т389 & $\uparrow$ & Belelovsky et al., 2005 \\
\hline \multirow{5}{*}{$\begin{array}{l}\text { CTA } \\
\text { Acquisition }\end{array}$} & CREB & $\mathrm{S} 133$ & $\uparrow$ & Swank, 2000 \\
\hline & NMDAR NR2B & Y1472 & $\uparrow$ & $\begin{array}{l}\text { Rosenblum et al., } \\
1995\end{array}$ \\
\hline & PKC & & $\uparrow$ & $\begin{array}{l}\text { Rodriguez-Duran and } \\
\text { Escobar, } 2014\end{array}$ \\
\hline & PSD-95 & & $\uparrow$ & Miyakawa et al., 1997 \\
\hline & TrkB & Y & $\uparrow$ & Ma et al., 2011 \\
\hline $\begin{array}{l}\text { CTA } \\
\text { Consolidatior }\end{array}$ & CaMKIIl & T286 & $\uparrow$ & $\begin{array}{l}\text { Adaikkan and } \\
\text { Rosenblum, } 2015\end{array}$ \\
\hline
\end{tabular}


acquisition and retrieval. Microinfusion of the GABAA receptor agonist, muscimol into the IC, suppresses the ability of a novel tastant to increase ERK phosphorylation, inhibiting synaptic plasticity required for taste memory formation (Berman et al., 2000). Conversely, microinfusion of the GABAAR antagonist bicuculline in the IC prior to water drinking, enhanced ERK phosphorylation, but neither affected drinking behavior itself (Berman et al., 2000). More recent studies have further demonstrated muscimol microinfusion into the rat agranular IC to suppress palatability-driven feeding, but not drinking itself (Baldo et al., 2016). This effect was characterized by a decrease in chocolate-shake intake and the duration of time spent ingesting chocolate shake, but did not affect water drinking or ingestion of standard chow in food-deprived rats (Baldo et al., 2016). It is thus likely that cholinergic activation of ERK within the IC during taste memory acquisition not only encompasses encoding of the novelty of the stimulus, but also the qualitative characteristic of the stimulus, which determines its relative consumption in future encounters (Adaikkan and Rosenblum, 2012).

GABAergic IC neurotransmission is also likely to influence the interception of CS-related cues that allow organisms to attribute salience and facilitate rapid decision making and behavioral modifications during sensory experience-based learning and retrieval (Baldo et al., 2016; Rodriguez-Garcia and Miranda, 2016). Muscimol microinfusion into the IC prior to CTA retrieval in rats suppressed aversion to the CS (Berman et al., 2000), but did not induce preference reminiscent of $\mathrm{AN}$ reported elsewhere (Lin and Reilly, 2012; Moraga-Amaro et al., 2014; Rodriguez-Garcia and Miranda, 2016). Taken together findings are consistent with GABAergic local circuits generating familiarity signals that inhibit the attribution of salience and palatability-driven behavior. Interestingly, increased GABAergic neurotransmission in the IC has been suggested to contribute to disruption of interoceptive awareness observed in major depression and anorexia nervosa patients (Wiebking et al., 2014).

Inhibitory GABAergic interneurons of the IC have also been involved in off-line processing following novel taste learning (Doron and Rosenblum, 2010). For example, GABAergic, $\mathrm{GAD}^{+} 7^{+}$neurons residing in the deep layers of the IC were shown to express increased $c$-fos immunoreactivity $2 \mathrm{~h}$ following appetitive novel taste learning (Doron and Rosenblum, 2010). GABAergic inhibition has also been observed to increase in response to novel sensory information during off-line processing in other regions responsible for the encoding of other modalities (McCasland and Hibbard, 1997; Staiger et al., 2002; Murayama et al., 2009). Increased IC GABAergic activation following novel taste consumption could be indicative of offline malaise-related computations that are required for $\mathrm{AN}$, as taste information is evaluated in relation to associated lower brain inputs (Dudai and Eisenberg, 2004; Doron and Rosenblum, 2010; Adaikkan and Rosenblum, 2015). One possibility might be that increased IC inhibition subserves the unique attribute of taste to be associated with visceral information in the subsequent hours (Rosenblum, 2008). Interestingly, microinfusion of both $\mathrm{GABA}_{B} \mathrm{R}$ agonists and antagonists into the IC was recently shown to disrupt recognition memory in mice, suggesting $G_{A B A_{B}} R$ balance in the IC to be critical for memory formation (Wu et al., 2017).
$\mathrm{GABA}_{\mathrm{B}} \mathrm{R}$-dependent neurotransmission has been previously reported to promote synaptic plasticity in hippocampal neurons through ERK-dependent mechanisms (Im and Rhim, 2012). However, the relevant contribution of metabotropic GABAergic receptor signaling in the different phases of taste learning is yet to be comprehensively addressed.

Another mechanism involved in novel taste learning is NMDAR activation. Microinfusion of NMDAR antagonist APV into the IC inhibits correlative ERK activation following novel taste experience, indicating that converge on ERK activation following novel taste learning (Berman et al., 1998, 2000; Gutiérrez et al., 2003a). However, this is likely to represent divergent processes that operate under distinct timescales during learning. Specifically, NMDAR activation is not necessary for novel taste learning and subsequent $\mathrm{AN}$, since these learning paradigms were found sensitive to blockade of cortical mAChRs, but not NMDAR blockade (Gutiérrez et al., 2003a). Earlier studies using muscarinic agonist carbachol have demonstrated muscarinic neurotransmission to additionally modulate phosphorylation of the NR2B subunit of NMDAR, and to contribute to ERK activation during novel taste memory formation (Rosenblum et al., 1996). NR2B phosphorylation is necessary for taste learning, and has been shown to inversely correlate with taste novelty (Nunez-Jaramillo et al., 2008; BarkiHarrington et al., 2009). However, NMDAR antagonism does not impair incidental taste memory formation, suggesting that novel taste memory encoding itself is not dependent on NR2Bmediated ERK phosphorylation (Gutiérrez et al., 2003a).

Consistent with the above, more recent work has demonstrated convergence of NMDAR and dopamine signaling pathways onto ERK in the IC following taste learning (David et al., 2014; Ramirez-Lugo et al., 2015). Specifically, dopamine has been shown to bind to its D1 receptor and to interact with the Y1472 domain of the NR2B NMDAR subunit to activate ERK during novel taste learning (David et al., 2014). Furthermore, intraperitoneal administration of the D1R agonist SKF38393 in NR2B F1472 mutant mice (where tyrosine phosphorylation is not possible) was associated with a suppression of both NR2B and ERK phosphorylation in the IC (David et al., 2014), suggesting that phosphorylation of Y1472 of the NR2B subunit of NMDAR following dopaminergic D1 receptor stimulation is not only correlated with the increase in ERK activation but necessary for it.

Indeed, NR2B tyrosine phosphorylation after learning promotes intracellular redistribution of the NMDAR population that promotes taste memory encoding during acquisition (Barki-Harrington et al., 2009). Yet, transgenic NR2B F1472 mice only display increased neophobia and delayed AN that diminishes following the second taste exposure, whereas associative learning, as tested using the CTA paradigm, is normal (David et al., 2014). Thus, dopaminergic activation of ERK in the IC via the NR2B subunit appears to contribute to the encoding of information regarding novel stimuli that is required for the AN, but not for taste recognition upon reconsolidation or association of CS-US (Levitan et al., 2016). Glutamate and dopamine reactivation has been reported in the insula during the consolidation of CTA memories, $45 \mathrm{~min}$ following the 
administration of a malaise-inducing US (Guzman-Ramos et al., 2010; Guzman-Ramos and Bermudez-Rattoni, 2012). It is thus likely that NR2B-dependent ERK plasticity operates during memory consolidation to facilitate the encoding of information modulating the expression of behavioral adjustments to the novel tastant, rather than taste familiarity itself.

Increases in pERK are upstream of ELK-1, a member of the ternary complex factor present at the serum response element for the promoter region of several IEGs, including $c$-fos (Hipskind et al., 1991; Treisman, 1995). The induction of IEGs in the IC is regulated by the parallel activation of plasticity-related signal transduction pathways (Table 3). For instance, in the case of $c$-fos, activation increases in response to novelty and diminishes with familiarity, near mirroring effects observed on pERK (Koh and Bernstein, 2005; Yefet et al., 2006). During novel taste memory learning, ELK-1 transcriptional activity in the IC induces the expression of the postsynaptic membrane95, membrane-associated guanylate kinase - PSD-95 (Yefet et al., 2006; Elkobi et al., 2008). PSD-95 is known to interact and regulate NMDAR trafficking and function (Lavezzari et al., 2003; Cousins et al., 2008). During novel taste learning, PSD-95 binds to phosphorylated NR2B and has been suggested to move along with the NMDAR into lipid raft membrane domains (Dong et al., 2004; Barki-Harrington et al., 2009). Increased pERKdependent transcriptional activity in the IC is thus essential in promoting structural modification of the synapse, required for the acquisition and persistence of taste memories.

Current data on novel-taste memory acquisition would suggest ACh-dependent ERK activation in the IC to remove plasticity constraints (Table 2), and to shift proteostasis toward more protein synthesis while reducing synaptic protein degradation (Rosenblum et al., 1993, 2000; Rosenberg et al., $2016 \mathrm{~b})$. These two effects of mAChR signaling converge on p70S6K, and both shift proteostasis toward more synthesis during a relatively short time period of acquisition. Increases in protein synthesis driven by $\mathrm{mAChR}$-dependent ERK activation in the IC are required for taste memory formation and are sufficient for AN (Levitan et al., 2016; Rosenberg et al., 2016b). Conversely, decreased protein synthesis facilitates memory retrieval that is resistant to IC NMDAR antagonism (Levitan et al., 2016). Whereas, the induction of $\mathrm{mAChR}$-dependent protein synthesis through ERK, minutes following a sensory experience, is required for the acquisition of novel taste information by the IC, NMDAR - CaMKII dependent up-regulation of proteasome activity $4 \mathrm{~h}$ later is necessary for associative learning (Rosenberg et al., 2016a,b).

Interestingly, timely decreases in mAChR-dependent ERK proteostasis activation during retrieval could be equally instrumental to memory maintenance (Rappaport et al., 2015). For example, mRNA expression of the endogenous negative regulator of taste learning $\mathrm{NRH}$ : quinone reductase 2 (QR2) (Benoit et al., 2010) was found to be down-regulated in a mAChR-dependent, NMDAR independent manner, and to promote taste memory stabilization (Rappaport et al., 2015). The mechanism through which mAChR signaling reduces QR2 expression to allow stronger memory acquisition remains unknown, but has opened a number of possibilities
TABLE 3 | Gene Expression at the IC modulated by Taste Learning

\begin{tabular}{llll}
\hline Learning paradigm & Gene & Effect & References \\
\hline Novel Taste Learning & Arc & Lateralization & Inberg et al., 2013 \\
& Arc & $\downarrow$ & Morin et al., 2011 \\
& Arc & - & Saddoris et al., 2009 \\
& C/EBP $\beta$ & $\uparrow$ & Merhav et al., 2006 \\
& c-fos & $\uparrow$ & Koh and Bernstein, \\
& C-fos & $\uparrow$ & $\begin{array}{l}\text { 2005 } \\
\text { Yefet et al., 2006 }\end{array}$ \\
& Homer & - & Saddoris et al., 2009 \\
\hline CTA Acquisition & Arc & $\uparrow$ & Barot et al., 2008 \\
\hline CTA Consolidation & Bdnf & $\uparrow$ & Ma et al., 2011 \\
\hline
\end{tabular}

relating to its potential as a target for improved memory and cognition.

\section{AVERSIVE TASTE MEMORY ENCODING AND THE INSULA}

Studies of learned aversion in the laboratory typically involve association of known appetitive novel tastants, such as sweet or salty water, with gastric discomfort (Nachman, 1970). Intraperitoneal administration of $\mathrm{LiCl}$ stimulates sensory portions of the vagus and splanchnic nerves innervating the gut producing signs of illness that serve as the US (Niijima and Yamamoto, 1994). Following CS-US pairing CS intake is suppressed, suggesting a conditioned downshift in taste palatability (Bures et al., 1998). Aversion to a number of bitter substances such as quinine and phenylthiocarbamide is unconditional in mammals, mediated through innate hereditary mechanisms (Kutscher and Wright, 1977; Kutscher et al., 1977; Whitney and Harder, 1986). The hereditary component of this behavioral response is understood to underlie sensory differences among individuals independent of the conditions associated with the initial encounter of stimulus in question. In this section we will focus on acquired taste responses and in particular CTA.

Conditioned and unconditioned responses to tastants differ in the neural processes that govern their expression (Dunn and Everitt, 1988; Spector, 1995; Spector and Glendinning, 2009). CTA acquisition, prior to permanent or pharmacological inactivation of the IC produces CTA amnesia and enhances latent inhibition of CTA in rats, even though familiarity can still be acquired (Moraga-Amaro et al., 2014). However, large areas of the IC can be damaged without affecting CTA memory (Hashimoto and Spector, 2014; Schier et al., 2014; Blonde et al., 2015). For example, specific bilateral lesions in the dIC and aIC were associated with significant CTA expression deficits, whereas lesions of the gIC were without effect, demonstrating regional specificity in the function of the IC during CTA memory formation (Schier et al., 2014, 2016; Lin et al., 2015). It could be surmised that reward, palatability and other safety signals generated in other regions during the encoding of appetitive taste memories are sufficient for the maintenance of appropriate behavioral responses for familiarity during retrieval. 
In a sense, the role of the IC may not be taste discrimination, but rather the shaping of complex behavioral responses through off-line computations that allow association with interoceptive information, facilitating retrieval.

The involvement of the cholinergic system in CTA acquisition was first reported more than 30 years ago, through the use of relatively large doses of the muscarinic antagonist atropine in rats (Kral, 1971; Deutsch, 1978). Cholinergic innervation arising from the basal forebrain complex is crucially involved in the ability of rats to learn aversively motivated tasks (Lopez-Garcia et al., 1993). Cholinergic and GABAergic innervation of the cortex arising from the basal forebrain complex was demonstrated to be necessary for the acquisition and consolidation of inhibitory avoidance memories (Lopez-Garcia et al., 1993; Miranda and Bermudez-Rattoni, 1999). This finding was extended to CTA acquisition, in studies where lesions of cholinergic basal-cortical and basal-amygdalar projections from the NBM to the IC disrupted CTA acquisition in rats (Gutiérrez et al., 1999b,c; Hasselmo and Giocomo, 2006).

Even though systemic scopolamine administration is of no consequence to CTA retrieval, its microinjection into the IC during the first $4 \mathrm{~h}$ following learning does abolish taste aversion for several days (Naor and Dudai, 1996; Berman et al., 2000; Gutiérrez et al., 2003a). Notably, an effect on short term memory and long term memory is only observed when microinjections are carried out prior to taste presentation during acquisition, but not prior to retrieval testing (Ferreira et al., 2002). Early and more recent studies have demonstrated $\mathrm{mAChR}$ - and dopaminergic NR2B-dependent signaling, to promote ERK activation minutes following novel taste consumption (Berman et al., 2000; David et al., 2014). Muscarinic activation of protein synthesis in the IC downstream of ERK following novel taste exposure is thus required in both appetitive and aversive memory acquisition (Nunez-Jaramillo et al., 2008). Pairing a stimulus with the release of either ACh (Gutiérrez et al., 1999b,c), or dopamine (DA) evokes long lasting increases in the responses of neurons to the paired stimulus (Bao et al., 2001; Schultz, 2010; Zellner and Ranaldi, 2010). Recent computational studies examining the representation and classification performance of a neural network, indicate $\mathrm{ACh}$ and DA to trigger distinct changes in neural representations to improve performance (Holca-Lamarre et al., 2017). Based on model data, the authors suggested that ACh redistributes stochastic neuronal selection so that more neurons encode stimulus classes that are challenging for the network, while DAergic signals adapt synaptic weights to match the classes of the task at hand.

Early pharmacological studies (Table 1), utilizing microinfusion of GABAA receptor antagonist bicuculline and GABA analog muscimol demonstrated GABAergic modulation of both CTA acquisition and retrieval (Berman et al., 2000). Both bicuculline and muscimol microinfusion into the IC prior to CTA training impaired subsequent acquisition and latent inhibition of CTA, but only muscimol elicited a deficit in CTA retrieval (Miranda et al., 2000; Moron et al., 2002). Inhibition of ERK phosphorylation in the IC by GABA likely hinders the interception of CS-related cues that encode salience and facilitate cognition required for CTA retrieval (Berman et al., 2000).
Transgenic mice lacking specific subtypes of the postsynaptic metabotropic, revealed that $\operatorname{GABAB}(1 \mathrm{a})$ knockout mice fail to acquire CTA, while $\mathrm{GABAB}(1 \mathrm{~b})$ knockouts fail to extinguish CTA (Jacobson et al., 2006). Systemic administration of the $\mathrm{GABA}_{\mathrm{B}}$ agonist baclofen has been demonstrated to act as an US for CTA training (Wilson et al., 2011), even though others have argued otherwise (Chester and Cunningham, 1999). Whether the aforementioned GABAB-dependent effects relate to activity within the insula is still under investigation.

GABAergic neurotransmission modulates activity in the IC through local networks, in concert with inputs from the NBM (Wood and Richard, 1982; Zaborsky et al., 1986) or through $\mathrm{GABA}_{\mathrm{A}}$ receptor activation in the NBM alone (Chu et al., 1990; DeSousa et al., 1994). Others have argued that the acquisition of CTA is primarily dependent on the parabranchial nucleus, which is the region in control of the release of familiarity and safety encoding GABA at the IC (Reilly, 1999). In studies where a number of brain regions thought to be involved in CTA acquisition and retention, dramatic deficits in the behavioral paradigms were induced by lesions of the $\mathrm{PBN}$, the thalamus and the BLA, as well as the GC and BLA in this order (Yamamoto et al., 1995). Our view is that the role of the GC cannot be limited to novelty detection or discrimination, as others have supported, but we also propose the GC to act as a hub, and not a "stand-alone" structure in the formation and persistence of internal representation relating to taste aversion.

Evidence of the rule of glutamate in CTA acquisition was first demonstrated by the systemic administration of noncompetitive and competitive NMDAR antagonists prior to saccharin exposure (Welzl et al., 1990; Willner et al., 1992). Glutamatergic projections to the IC from the amygdala are currently well recognized for their role in aversive taste memory formation (Everitt and Robbins, 1997; Gutiérrez et al., 2003b; Ferreira et al., 2005). Injection of $\mathrm{LiCl}$ or the arrival of appropriate malaise-reporting visceral inputs in the subsequent hour following taste exposure elicits increases in glutamate release in the IC that is instrumental to CTA memory consolidation (Table 1). In vivo microdialysis and capillary electrophoresis studies have suggested these effects in the IC to be downstream of amygdala-dependent glutamate and dopamine reactivation 45 min following CTA learning (Guzman-Ramos et al., 2010; Guzman-Ramos and Bermudez-Rattoni, 2012).

BLA-IC LTP enhances CTA memory persistence, but can be blocked by intraperitoneal administration of NMDAR antagonists 3 (2-carboxypiperazin-4-yl) propyl-1 phosphoric acid (CPP) and dizocilpine maleate (MK-801) (Escobar and Alcocer, 1998; Escobar and Bermudez-Rattoni, 2000). NMDAR blockade in the IC prior to taste presentation is only of consequence to CTA long term memory but not short term memory, consistent with the temporal time frame of NMDARdependent LTP (Ferreira et al., 2002). The characteristic role of the NMDAR during LTP is thought to underlie the encoding of associative signals essential for CTA consolidation following acquisition training (Davis et al., 1992; Escobar et al., 1997). Bilateral microinjection of the NMDAR antagonist 2-amino-5phosphonopentanoic acid (AP5) into the IC, however, disrupts 
CTA memory formation, but is inconsequential to incidental taste learning (Gutiérrez et al., 1999a, 2003a). In further support, NMDAR antagonism of the IC was shown to disrupt both short term memory and long term memory of CTA only when carried out following $\mathrm{LiCl}$ administration (Ferreira et al., 2005). As more recent studies in rats demonstrated, NMDAR-dependent signaling is required for the maintenance of a short-term $(3 \mathrm{~h})$ memory trace in the $\mathrm{IC}$, that is required for the development of the association between the CS and US (Adaikkan and Rosenblum, 2015). This NMDAR-dependent IC memory trace modulates CTA acquisition within conditioning inter-stimulus intervals (ISI) of up to $3 \mathrm{~h}$ (Adaikkan and Rosenblum, 2015).

Tyrosine phosphorylation of the NMDAR subunit NR2B and NMDAR-dependent increases in PSD-95 have also been reported to increase in response to CTA training (Rosenblum et al., 1995; Miyakawa et al., 1997). NR2B phosphorylation in response to CTA training was shown to be a function of the novelty of the taste stimulus, the quantity of the taste substance consumed, as well as the efficacy of the taste as a CS to become aversive (Rosenblum et al., 1995; Miyakawa et al., 1997).

LTP in the BLA-IC projection prior to CTA training facilitates its retention, while promoting a protein-synthesis dependent suppression of LTP in the BLA-IC pathway in the subsequent $120 \mathrm{~h}$ (Escobar and Bermudez-Rattoni, 2000; Rodriguez-Duran et al., 2011). This characteristic effect of CTA acquisition on subsequent IC plasticity is susceptible to local blockade of the NMDAR, as well as the inhibition of PKC (but not PKA) (Rodriguez-Duran and Escobar, 2014). NR2B tyrosine phosphorylation during acquisition is thus likely to prime activated synapses to incorporate circuit-wide associative input during consolidation through NMDAR-dependent synaptic potentiation (Ferreira et al., 2005).

Importantly, the development of this short-term memory trace during novel taste learning alone correlates with upregulation of T286 CaMKII $\alpha$ phosphorylation in synaptosomal fractions of the IC (Adaikkan and Rosenblum, 2015). However, NMDAR-dependent T286 CaMKII $\alpha$ phosphorylation is dispensable to incidental taste learning itself, and only influences the maintenance of the CS-US association during CTA training with ISIs of up to $3 \mathrm{~h}$ (Adaikkan and Rosenblum, 2015). A separate cluster of rats acquired significant, but weaker aversion to saccharin even during conditioning with an ISI of $4-8 \mathrm{~h}$, which was not susceptible to inhibition of IC CaMKII $\alpha$. Behavioral responses observed in this cluster of animals exhibit similarities to animals that were subject to pharmacological inhibition of components of the plasticity-related signaling in the IC (Rosenblum et al., 1993; Barki-Harrington et al., 2009; Parkes et al., 2014). In addition, increased susceptibility to extinction was observed in the ISI of $5-8 \mathrm{~h}$ compared to the ISI of 1-3h clusters (Adaikkan and Rosenblum, 2015). This and other findings (Table 2), thus suggest the balance of NMDAR-dependent and independent plasticity at the IC to influence the dominance of aversive memory traces (Koh et al., 2009; Hashikawa et al., 2013; Marotta et al., 2014).

Other components of the glutamatergic system, such as ionotropic AMPA receptors incorporate plasticity-related signals from lower brain centers (Berman et al., 2000; Yasoshima et al.,
2000). For example, glutamatergic release from the BLA to the IC during CTA retrieval is attenuated by both NMDAR and AMPAR-antagonism (Yasoshima et al., 2000). However, CTA retrieval is only susceptible to AMPAR antagonism of the IC, unlike other forms of glutamatergic receptor antagonism (Berman et al., 2000). Furthermore, unlike blockade of the NMDAR-CaMKII $\alpha$ effects, CNQX (competitive AMPA/kainate receptor antagonist) microinfusion into the IC $1 \mathrm{~h}$ following novel taste learning suppresses CTA retrieval even when the US is delivered $4 \mathrm{~h}$ later (Adaikkan and Rosenblum, 2015). On the other hand, microinfusion of CNQX into the amygdala disrupts CTA expression and suppresses norepinephrine and dopamine augmentations in the IC (Osorio-Gomez et al., 2016). Novel taste learning itself induces up-regulation of the GluR1 AMPAR subunit, while AMPAR trafficking and signaling in the IC influences the ability of long-term memory trace inputs to form negative CS-US associations (Adaikkan and Rosenblum, 2015; Osorio-Gomez et al., 2016). AMPAR-dependent activity in the IC might underlie the ability of the brain to encode the aversion expected by a sensory experience and to re-evaluate its relevant weight in predicting the US in relation to inputs arising from the extended taste learning circuit upon subsequent consolidation trials (Eisenberg et al., 2003).

CTA acquisition, but not retrieval, can also be disrupted by either mGluR5-specific or Group II-III mGluR antagonist (MCPG) IC infusion prior to training (Berman et al., 2000; Bills et al., 2005). Conversely, only microinfusion of MCPG was associated with increased aversion during latent inhibition testing (Berman et al., 2000). More recently, microinfusion of mGluR1 antagonist AIDA into the IC at 0,30 , but not $60 \mathrm{~min}$ prior to taste presentation accelerated the $\mathrm{AN}$ in rats, whereas analogous infusion of glutamate impaired AN (Ramirez-Lugo et al., 2015). GluR1 activation following taste learning likely relates to the expression of a time-restricted warning signal in the IC, which restrains $\backslash$ s uncontrolled intake upon encounter of a novel stimulus in fear of potentially unsafe post-ingestive consequences (Ramirez-Lugo et al., 2015).

Findings might be indicative of opposing roles for Group I and Group II-III mGluRs during taste memory formation. Group I mGluR activation in the IC appears to interact with CS-dependent and preceding US-dependent glutamatergic neurotransmission to promote CTA learning through BLA-IC LTP (Guzman-Ramos and Bermudez-Rattoni, 2012). Given that latent inhibition is inhibited by MCPG and the opposing effects of Group I and Group II-III mGluR signaling on cAMP (Barros et al., 2000; Berman et al., 2000; Page et al., 2006), it is possible that regulation of cAMP through mGluRs at the IC modulates the formation of associations during acquisition (Escobar et al., 2002). However, distinct processes might dictate AN and LI, and the role of Group II-III mGluRs in appetite taste memories should be examined separately.

Interestingly, recent studies of LTP and LTD in slices of the BLA have demonstrated that application of mGluR1 agonist DHPG promotes the induction of LTP following single pulse theta-burst stimulation (Chen et al., 2017). Palatability signals generated in the BLA and relayed to the IC could thus incorporate this early novelty-detecting warning signal through 
mGluR-dependent mechanisms (Chen et al., 2013; RamirezLugo et al., 2015). The reported priming effect of DHPG on subsequent BLA LTP is susceptible to mGluR5 antagonism, is PLC-dependent, and partially dependent on PKC (Chen et al., 2017; Rodriguez-Duran et al., 2017). The suppression of IC LTP following CTA acquisition is susceptible to local blockade of the NMDAR, as well as the inhibition of PKC (but not PKA), that could further implicate mGluR signaling (RodriguezDuran and Escobar, 2014). mGluR-dependent regulation of PKC levels in the IC during novelty might participate in CTA memory consolidation through BLA-IC LTP (Rodriguez-Duran and Escobar, 2014; Ramirez-Lugo et al., 2015).

\section{LEARNING AND RE-LEARNING IN THE INSULA}

Memory consolidation, a progressive process of post-acquisition stabilization that facilitates the permanent storage of memory, is dependent on the gene expression and synthesis of new proteins within relevant brain structures (Davis and Squire, 1984; Kandel, 2001, 2012). A diverse repertoire of plasticity is expressed in glutamatergic synapses in response to synaptic input, including several mechanistically distinct kinds of synaptic potentiation and depression, as well as homeostatic synaptic scaling (Lee et al., 2005; Park et al., 2006; Wibrand et al., 2006). Activity-dependent local synthesis and degradation of proteins is thought to translate synaptic inputs into remodeling of synaptic composition, and dendritic spine function (Steward and Shuman, 2003; Bramham and Wells, 2007).

Plasticity-related molecular signaling regulates transcription factors such as CREB and Elk-1 (Table 3), regulate IEGs shaping the genetic program through which memories are consolidated (Guzowski et al., 1999; Okuno, 2011). Induced by CREBdependent transcription, the brain-derived neurotrophic factor (BDNF) regulates neuronal activity, differentiation, and learningrelated plasticity (Barde et al., 1987; Leibrock et al., 1989; Huang and Reichardt, 2001; Chao, 2003). BDNF modulates synaptic plasticity through phosphorylation of the NR1 and NR2B NMDAR subunits via PKC and ERK (Iwasaki et al., 1998; Mizuno et al., 2003). Importantly, BDNF promotes AMPAR trafficking and stability at the synapse, via PKC and CAMKII $\alpha$ (Wu et al., 2004), inhibiting GABAergic inhibitory post-synaptic potentials (Henneberger et al., 2002).

Inhibition of BDNF protein secretion or signaling impairs memory acquisition, retention, and recall in hippocampus- and amygdala-dependent learning paradigms (Linnarsson et al., 1997; Minichiello et al., 1999; Alonso et al., 2002; Rattiner et al., 2004). Studies of the role of BDNF signaling in CTA acquisition, demonstrated CREB-dependent increases in the CeA and IC to occur $12 \mathrm{~h}$ following conditioning (Swank, 2000; Desmedt et al., 2003; Ma et al., 2011). BDNF infusion into the IC, previously known to revert CTA memory impairments induced by protein inhibition (Miguel-Gonzalez et al., 2008), was more recently shown to convert a weak CTA to a strong one when administered following training (Martinez-Moreno et al., 2016). The induction of BDNF transcription is thus likely to facilitate aversive taste memory formation through BLA-IC LTP, while BDNF protein expression in the IC appears to confer memory maintenance and stability of predicted CS-US associations.

Another important target of CREB transcription is the gene coding for the activity regulated cytoskeleton-associated protein, Arc/Agr3.1 (Guzowski et al., 2000; Waltereit et al., 2001). Arc is an activity-regulator effector IEG that exhibits dependence on excitatory glutamatergic transmission (Link et al., 1995; Lyford et al., 1995; Guzowski et al., 2001). Extensive studies in the rat hippocampus have indicated Arc induction and translation to be required for AMPAR endocytosis typically observed during the transition from LTP to LTD (Guzowski et al., 2000; Chowdhury et al., 2006; Plath et al., 2006; Bramham et al., 2008). Interactions of Arc with endocytic proteins endophilin and dynamin, form the post-synaptic trafficking endosome for AMPARs, essential for homeostatic plasticity maintenance (Chowdhury et al., 2006). In activated excitatory synapses, mGluR-dependent LTD induction is facilitated by increases in elongation factor 2-dependent translation of newly activated Arc, promoting cytoskeletal adaptations required for LTP consolidation (Kanhema et al., 2006; Messaoudi et al., 2007; Park et al., 2008; Jakkamstti et al., 2013).

Homer1a, much like Arc, is enriched in excitatory synapses and its translation mediates structural changes at the postsynaptic density that are instrumental to activity-dependent neuronal plasticity and development (Brakeman et al., 1997; Xiao et al., 1998; Garner et al., 2000). Constitutively expressed Homer isoforms bind to mGluR1 and link to the postsynaptic density through C-terminal coiled-coil (CC) multimers (Brakeman et al., 1997). The IEG Homerla, however, is an inducible truncated isoform that inhibits CC multimer formation. This in turn promotes mGluR interactions with endoplasmic-reticulum resident inositol triphosphate receptors (IP3Rs), leading to enhanced $\mathrm{Ca}^{2+}$-dependent intracellular activity (Tu et al., 1998, 1999). In addition, Homer1a complexes with PSD-95 and Shank, to physically link mGluR5 and NMDAR-signaling, an important event during late phase LTP (Naisbitt et al., 1999; Fowler et al., 2011).

Arc and Homerla are NMDAR-dependent plasticity markers that exhibit differential temporal expression patterns in activated neurons (Guzowski and Worley, 2001; Guzowski et al., 2001). In the BLA itself, CS- and US-specific increases in Arc mRNA have been demonstrated minutes following CTA training (Barot et al., 2008). Similarly, in the IC, Arc as well as Homer1a mRNA expression is differentially up-regulated within minutes of incidental novel but not familiar sucrose tasting (Saddoris et al., 2009). Furthermore, indicative of a role in the formation of predictions during retrieval through IC IEG induction, presentation of CS-related odor cues alone induced similar increases in Arc and Homerla to the CS itself (Saddoris et al., 2009). Importantly, lesions of the BLA only attenuated, but did not inhibit this effect, suggesting the induction of NMDARdependent IEGs at the IC encompass information out with palatability and hedonic value inputs arising from the amygdala.

Okuno et al. have demonstrated Arc to be captured at less active synapses, a phenomenon known as inverse synaptic tagging (Okuno et al., 2012). This localization of Arc is mediated by high-affinity binding to inactive CaMKII $\beta$, resulting in AMPAR endocytosis and spine shrinkage (Kim et al., 2012; 
Okuno et al., 2012). Studies indicate that such signaling events are likely to be key to the formation of the short-term taste memory trace at the IC, that is required for CS-US association and effective CTA memory formation (Adaikkan and Rosenblum, 2015). Even though elegant studies using catFISH were not able to demonstrate coincidence detection of CS and US through changes in subcellular Arc mRNA expression at the IC, it is likely that occur at different times points at the BLA and the IC toward the maintenance of homeostatic scaling (Turrigiano, 2012; Vitureira et al., 2012). It would particularly interesting to examine how manipulation of signaling events such as NMDAR-CAMKII-AMPAR (Adaikkan and Rosenblum, 2015) or MAPK pathway (Elkobi et al., 2008), affect the memory process through changes in Arc transcription, translation and sub-cellular localization (Bluthgen et al., 2017; Nikolaienko et al., 2017a,b).

Conversely, studies have argued for CREB-independent gene transcription in the IC during novel taste learning (Swank, 2000; Desmedt et al., 2003; Yefet et al., 2006). Despite induction of cytoplasmic Arc mRNA at the IC following CS administration (Barot et al., 2008), consumption of novel sweet or salty water in rats had no overall effect on Arc protein IC expression $1 \mathrm{~h}$ following tasting (Inberg et al., 2013). Interestingly, Arc protein expression was lateralized $1 \mathrm{~h}$ following novel, but not familiar taste consumption. Increased Arc expression was observed in the right hemisphere in about $50 \%$ of the animals, whereas the remaining animals showed increased expression in the left hemisphere (Inberg et al., 2013). Importantly, Arc protein lateralization was evident in the background of significant ERK activation known to indirectly promote Arc transcription via CREB (Teber et al., 2004; Huang et al., 2007; Adaikkan and Rosenblum, 2012).

Complementary studies accounting for hydration-induced rapid increases in Arc mRNA in the IC, demonstrated novel taste learning to promote prolonged suppression of $A r c$ transcription (Inberg et al., 2016). Rapid induction of pERK upon stimulation and the sharp initial induction of $\operatorname{Arc}$ mRNA in response to hydration alone might suggest ERK activation to underlie drinking-induced increases in Arc mRNA independently of taste learning-induced suppression (Inberg et al., 2016). Novel taste learning-induced suppression of Arc mRNA extends up to $6 \mathrm{~h}$ following consumption, despite increases in the number of differentially modulated genes compared to water consumption (Inberg et al., 2016). Arc has thus served to highlight the requirement, but also the complexity and spatiotemporal precision of taste learning-related computations mediated by transcription in the IC (Tzingounis and Nicoll, 2006; Bramham et al., 2008).

Novel taste-induced decreases in mRNA expression could relate to necessary adjustments toward levels that are required for optimal synaptic plasticity, achieved upon acquisition of familiarity (Inberg et al., 2016). Given previous reports regarding the ability of BLA-IC LTP in CTA acquisition, Arc transcription in the IC might be specific to computations regarding the expectation of negative experiences (Jones et al., 1999; Ying et al., 2002; Kanhema et al., 2006). CTA memory formation and retrieval require CREB-dependent increases in Arc expression in specific neurons of the IC and BLA (Barot et al., 2008; Sano et al., 2014). CTA memory formation exhibits ionotropic NMDAR dependency, which is likely promotes CREB transcription via PKC (Miranda and McGaugh, 2004; Adaikkan and Rosenblum, 2012; Rodriguez-Duran and Escobar, 2014). Increased cortical Arc mRNA expression was reported in mice classified as slow learners, exceeding levels recorded by autoradiography in overtrained animals (Kelly and Deadwyler, 2002, 2003). Subsequently translated Arc protein in specific neurons of the IC, consistent with the inverse synaptic postulate regarding the consolidation and maintenance of aversive memories (Kim et al., 2012), decreasing the capacity for behavioral plasticity to the CS.

Indicative of a requirement for lateralization of IC Arc expression during incidental taste learning in rats, the effect subsides upon repeated exposures to the same tastant (Inberg et al., 2013). Furthermore, unilateral and bilateral infusions of the IC with protein inhibitors, induced similar impairments on CTA acquisition (Inberg et al., 2013). Lateralization of sensory responses, has also been reported in a number of species of the evolutionary tree (Galati et al., 2001; Royet and Plailly, 2004; Taha et al., 2007; Concha et al., 2012). In separate studies, lateralization of Arc protein expression in the BLA has been reported during the processing of positive and negative emotional learning conditions (Young and Williams, 2013). In this study, fear conditioning was associated with increased Arc expression in the right, but not in the left BLA, while reward magnitude increased Arc expression in the left, but not the right BLA (Young and Williams, 2013). Earlier studies of brain activity during taste exposure in humans, reported increased fMRI activity in the left IC of right handed individuals and vice versa (Faurion et al., 1999). More recent imaging studies in adult males, suggest lateralized computations to encode taste presence, pleasantness and concentration (Dalenberg et al., 2015).

The specific evolutionary benefit in such lateralized computations is still a matter of debate (Halpern et al., 2005; Lust et al., 2011). It is possible that Arc lateralization in the IC relates not only in the encoding of novelty of sensory stimuli during incidental taste learning, but might also represent a state permissive to re-learning, where the association of the CS-US association is still labile. Subsets of valence-specific engram-bearing neurons have been identified through their transcriptional profile in the amygdalar complex (Kim et al., 2016, 2017). The bidirectional connectivity of the IC with these valence-specific neuronal populations of the BLA and CeA is yet to be examined, and could be particularly revealing of circuit-wide adaptations in everyday life and disease-related transcriptional activity.

Other studies have reported increases in Arc protein expression in dendrites of the GC when comparing familiar and novel saccharin (Morin et al., 2011). This finding would not necessarily be inconsistent with aforementioned studies, reporting increases in Arc mRNA in response to incidental but not novel taste learning (Saddoris et al., 2009; Inberg et al., 2013, 2016), but might suggest differential modulation of familiarity and novelty through transcription and translation (Adaikkan and Rosenblum, 2015). When considering the role of Arc at the post-synaptic density (Park et al., 2008) and aforementioned 
characteristics of BLA-IC LTP during CTA (Ramirez-Lugo et al., 2015), Arc expression in the IC could be indicative of "what the subject knows about the experience" and to act as a restrain to further learning through favoring AMPAR endocytosis and mGluR-dependent LTD (Gil et al., 1997; Kimura, 2000).

Studies examining transcription and relevant protein expression during extinction and reinstatement of CTA might be more revealing of circuit-wide adaptations that underlie subjective interpretation of sensory experiences and more closely model natural settings. Extinction and reinstatement of conditioned responses is a dynamic process in which the activity of particular brain regions changes, depending on the extent to which the conditioned response has been extinguished (Bouton, 1994; Lee et al., 2013). Extinction and reinstatement of CTA have only been examined by a few studies, while the precise role of the insula in this presumably cortical-dependent paradigm remains elusive. Similarly to fear conditioning, plasticity and activity within the mPFC has been heavily implicated in CTAE (Morgan and LeDoux, 1993). Sakata et al. reported that mutant mice with selective disruption of activity-dependent, plasticity-promoting BDNF expression in prefrontal cortex, impairs the extinction of CTA (Sakata et al., 2013). Nonetheless some differences in temporal correlation of the engagement of relevant sub-regions have already been noted. For example, unlike fear extinction, CTAE depends on functional protein synthesis but not on NMDA receptor activation in the ventromedial prefrontal cortex (Akirav et al., 2006). In further support, Mickley et al. noted that unlike fear extinction (where Infralimbic mPFC increases in relation to Prelimbic), CTAE induces increased expression of c-fos in both the Infralimbic and Prelimbic mPFC (Mickley et al., 2005). In follow-up studies from the same group, unlike fear extinction and reinstatement, activation of the CeA, reflected by c-fos immunoreactivity was not affected by CTAE or increased by spontaneous recovery (Mickley et al., 2007). Furthermore, CTAE was correlated with increased c-fos expression in the GC and $\mathrm{mPFC}$, which was suppressed by spontaneous recovery of CTA (Mickley et al., 2007).

CTAE represents an inhibitory form of learning modulated by GABAergic signaling at the IC (Akirav et al., 2006). Conversely, activation of PI3-K signaling was reported to contribute to CTA maintenance and reinstatement (Slouzkey et al., 2013). Interestingly, the microinfusion of the IC with BDNF following CTA acquisition, accelerated CTAE (Rodriguez-Serrano et al., 2014), which others have suggested to be at least in part BLA-dependent (Xin et al., 2014). BDNF in the IC has been suggested to initiate CTAE without altering the original memory-trace (Xin et al., 2014), and to facilitate plasticity

\section{REFERENCES}

Abdolahi, A., Williams, G., Benesch, C., Wang, H., Spitzer, E., Scott, B., et al. (2017). Immediate and sustained decrease in smoking urges after acute insular cortex damage. Nicotine Tob. Res. 19, 756-762. doi: 10.1093/ntr/ ntx046 encoding the hedonic value of the CS in the absence of reinforcement (Furini et al., 2014). When considering findings suggesting LTP and LTD BLA-IC projection to exert bidirectional modulation of behavior (Rodriguez-Duran et al., 2017), it would be particularly interesting to examine whether and how this circuit encompasses hedonic and emotional processing. Other studies have suggested activity within the mPFC-IC (Jezzini et al., 2013; Gonzalez et al., 2015; Baldo et al., 2016) and orbitofrontal cortex-IC (Ramirez-Lugo et al., 2016) circuits to influence how motivation and choice-related computations are shaped. The precise temporal and cell-type specific plasticity within the IC could thus be pivotal to circuit-wide dynamics, determining the hedonic value and dominance of subjective engrams modulating behavior (Vincis and Fontanini, 2016; Avery et al., 2017).

Understanding the role of plasticity synaptic within distinct regions and the extended taste circuit during aversive taste CTAE, hold particular potential in explaining how associations regarding the salience and hedonic value of stimuli are modified in relation to experience. Data accumulated thus far is largely correlative, but encouragingly studies are increasingly able to address causality at the circuit level (Kim et al., 2016; Rajasethupathy et al., 2016; Roth, 2016). Imaging studies in humans, have heavily implicating the IC in self-referential processes shaping conscious awareness (Kurth, 2010; Critchley and Seth, 2012; Pais-Vieira et al., 2016). Further studies of the local activity and functional connectivity of the IC thus hold particular promise in relation to their link to autism (Odriozola et al., 2016), panic disorders (Banzett et al., 2000; Brannan et al., 2001), anorexia nervosa (Rolls, 1989, 2005; Shelley and Trimble, 2004), pain insensitivity (Singh et al., 2006; Potvin and Marchand, 2008), schizophrenia (Allen et al., 2004; Stephane et al., 2010), as well as alcohol and nicotine addiction (Fuehrlein et al., 2014; Abdolahi et al., 2017; Addicott et al., 2017).

\section{AUTHOR CONTRIBUTIONS}

All authors listed have made a substantial, direct and intellectual contribution to the work, and approved it for publication.

\section{FUNDING}

This work was supported by the Israeli Ministry of Science, Technology, and Space (MOST 3-12080), Israel Science Foundation (ISF-UGC 2311/15 and ISF-IDRC 2395/15) grants to KR. 
Adaikkan, C., and Rosenblum, K. (2012). The role of protein phosphorylation in the gustatory cortex and amygdala during taste learning. Exp. Neurobiol. 21, 37-51. doi: 10.5607/en.2012.21.2.37

Adaikkan, C., and Rosenblum, K. (2015). A molecular mechanism underlying gustatory memory trace for an association in the insular cortex. Elife 4:e07582. doi: 10.7554/eLife.07582

Addicott, M., Oliver, J., and Joseph McClernon, F. (2017). Nicotine increases anterior insula activation to expected and unexpected outcomes among nonsmokers. Psychopharmacology 234, 1145-1154. doi: 10.1007/s00213-017-4550-8

Akirav, I., Katsrinov, V., Vouimba, R., Merhav, M., Ferreira, G., Rosenblum, K., et al. (2006). Extinction of conditioned taste aversion depends on functional protein synthesis but not on NMDA receptor activation in the ventromedial prefrontal cortex. Learn. Mem. 13, 254-258. doi: 10.1101/lm.191706

Alberini, C. (2011). The role of reconsolidation and the dynamic process of long-term memory formation and storage. Front. Behav. Neurosci. 5:12. doi: $10.3389 /$ fnbeh.2011.00012

Allen, G., Saper, C., Hurley, K., and Cechetto, D. (1991). Organization of visceral and limbic connections in the insular cortex in the rat. J. Comp. Neurol. 311, 1-16. doi: 10.1002/cne.903110102

Allen, P., Johns, L., Chy, F., Broome, M., Vythelingum, G., and McGuire, P. (2004). Misattribution of external speech in patients with hallucinations and delusions. Schizophrenia Res. 69, 277-287. doi: 10.1016/j.schres.2003.09.008

Alonso, M., Vianna, M. R. M., Depino, A. M., Mello e Souza, T., Pereira, P., Szapiro, G., et al. (2002). BDNF-triggered events in the rat hippocampus are required for both short- and long-term memory formation. Hippocampus 12, 551-560. doi: 10.1002/hipo.10035

Arroyo, S., Bennett, C., Aziz, D., Brown, S., and Hestrin, S. (2012). Prolonged disynaptic inhibition in the cortex mediated by slow, non-alpha7 nicotininc excitation of a specific subset fo cortical interneurons. J. Neurosci. 32, 3859-3864. doi: 10.1523/JNEUROSCI.0115-12.2012

Avery, J. A., Gotts, S. J., Kerr, K. L., Burrows, K., Ingeholm, J. E., Bodurka, J., et al. (2017). Convergent gustatory and viscerosensory processing in the human dorsal mid-insula. Hum. Brain Mapp. 38, 2150-2164. doi: 10.1002/hbm.23510

Bailey, C. H., Kandel, E. R., and Si, K. (2004). The persistence of long-term memory: a molecular approach to self-sustaining changes in learning-induced synaptic growth. Nueron 44, 49-57. doi: 10.1016/j.neuron.2004.09.017

Baldo, B., Spencer, R., Sadeghian, K., and Mena, J. (2016). GABA-mediated inactivation of medial prefrontal and agranular insular cortex in the rat: contrasting effects on Hunger- and Palatability-driven feeding. Neuropsychopharmacology 41, 960-970. doi: 10.1038/npp.2015.222

Bales, M., Schier, L., Blonde, G., and Spector, A. (2015). Extensive gustatory cortex lesions significantly impair taste sensitivity to KCL and Quinine but not to sucrose in rats. PLoS ONE 10:e013419. doi: 10.1371/journal.pone.0143419

Baliki, M., Geha, P., and Apkarian, A. (2009). Parsing pain perception between nociceptive representation and magnitude estimation. J. Neurophysiol. 101, 875-887. doi: 10.1152/jn.91100.2008

Banzett, R., Mulnier, H., Murphy, K., Rosen, S., Wise, R., and Adams, L. (2000). Breathlessness in humans activates insular cortex. Neuroreport 11, 2117-2120. doi: 10.1097/00001756-200007140-00012

Bao, S., Chan, V., and Merzenich, M. (2001). Cortical remodelling induced by activity of ventral tagmental dopmaine neurons. Nature 412, 79-83. doi: $10.1038 / 35083586$

Barde, Y., Davies, A., Johnson, J., Lindsay, R., and Thoenen, H. (1987). Brain derived neurotrophic factor. Prog. Brain Res. 71, 185-189. doi: 10.1016/S0079-6123(08)61823-3

Barki-Harrington, L., Elkobi, A., Tzabary, T., and Rosenblum, K. (2009). Tyrosine phosphorylation of the 2B subunit of the NMDA receptor is necessary for taste memory formation. J. Neurosci. 29, 9219-9226. doi: 10.1523/JNEUROSCI.5667-08.2009

Barnett, S. (1958). Experiments on "neophobia" in wild and laboratory rats. Brit. J. Psychol. 49, 195-201. doi: 10.1111/j.2044-8295.1958.tb00657.x

Barot, S., Kyono, Y., Clark, E., and Bernstein, I. (2008). Visualizing stimulus convergence in amygdala neurons during associative learning. Proc. Natl. Acad. Sci. U.S.A. 105, 20959-20963. doi: 10.1073/pnas.0808996106

Barros, D., Izquierdo, L., Mello e Souza, T., Ardenghi, P., Pereira, P., Medina, J., et al. (2000). Molecular signalling pathways in the cerebral cortex are required for retrieval of one-trial avoidance learning in rats. Behav. Brain Res. 114, 183-192. doi: 10.1016/S0166-4328(00)00226-6

Belelovsky, K., Elkobi, A., Kaphzan, H., Nairn, A., and Rosenblum, K. (2005). A molecular switch from translational control in taste memory consolidation. Eur. J. Neurosci. 22, 2560-2568. doi: 10.1111/j.1460-9568.2005.04428.x

Belelovsky, K., Kaphzan, H., Elkobi, A., and Rosenblum, K. (2009). Biphasic activation of the mTOR pathway in the gustatory cortex is correlated with and necessary for taste learning. J. Neurosci. 29, 7424-7431. doi: 10.1523/JNEUROSCI.3809-08.2009

Benoit, C., Bastianetto, S., Brouillette, J., Tse, Y., Boutin, J., Delagrange, P., et al. (2010). Loss of quinone reductase 2 function selectively facilitates learning behaviors. J. Neurosci. 30, 12690-12700. doi: 10.1523/JNEUROSCI.2808-10.2010

Berlucchi, G., Moro, V., Guerrini, C., and Aglioti, S. (2004). Dissociation between taste and tactile extinction on the tongue after right brain damage. Neuropsychologia 42, 1007-1016. doi: 10.1016/j.neuropsychologia.2004.01.003

Berman, D., Hazvi, S., Neduva, V., and Dudai, Y. (2000). The role of identified neurotransmitter systems in the response of insular cortex to unfamiliar taste: activation of ERK1-2 and formation of a memory trace. J. Neurosci. 20, 7017-7023.

Berman, D., Hazvi, S., Rosenblum, K., Seger, R., and Dudai, Y. (1998). Specific and differential activation of mitogen-activated protein kinase cascades by unfamiliar taste in the insular cortex of the behaving rat. J. Neurosci. 18, 10037-10044.

Berman, D. E., Hazvi, S., Stehberg, J., Bahar, A., and Dudai, Y. (2003). Conflicting processes in the extinction of conditioned taste aversion: behavioral and molecular aspects of latency, apparent stagnation, and spontaneous recovery. Learn. Mem. 10, 16-25. doi: 10.1101/lm.53703

Bermudez-Rattoni, F. (2004). Molecular mechanisms of taste-recognition memory. Nat. Rev. Neurosci. 5, 209-217. doi: 10.1038/nrn1344

Bermudez-Rattoni, F. (2014). The forgotten insular cortex: its role on recognition memory formation. Neurobiol. Learn. Mem. 109, 207-216. doi: 10.1016/j.nlm.2014.01.001

Bermudez-Rattoni, F., and McGaugh, J. (1991). Insular cortex and amygdala lesions differentially affect acquisition on inhibitory avoidance and conditioned taste aversion. Brain Res. 549, 165-170. doi: 10.1016/0006-8993(91)90616-4

Bi, A. L., Wang, Y., Zhang, S., Li, B., Sun, Z., Bi, H., et al. (2015). Myosin II regulates actin rearrangement-related structural synaptic plasticity during conditioned taste aversino memory extinction. Brain Struct. Funct. 220, 813-825. doi: 10.1007/s00429-013-0685-5

Bielavaska, E., and Roldan, G. (1996). Ipsilateral connections between the gustatory cortex, amyglada and parabranchial nucleus are necessary for acquisition and retrieval of conditioned taste aversion in rats. Behav. Brain Res. 81, 25-31. doi: 10.1016/S0166-4328(96)00039-3

Bills, C., Schachtman, T., Serfozo, P., Spooren, W., Gasparini, F., and Simonyi, A. (2005). Effects of metabotropic glutamate receptor 5 on latent inhibition in conditioned taste aversion. Behav. Brain Res. 157, 71-78. doi: 10.1016/j.bbr.2004.06.011

Bliss, T., and Lomo, T. (1973). Long-lasting potentiation of synaptic transmission in the dentate are of the anaesthetized rabbit following stimulation of the perforant path. J. Physiol. 232, 331-356. doi: 10.1113/jphysiol.1973.sp0 10273

Blonde, G., Bales, M., and Spector, A. (2015). Extensive lesions in rat insular cortex significantly disrupt taste sensitivity to $\mathrm{NaCl}$ and $\mathrm{KCl}$ and slow salt discrimination learning. PLOS ONE 10:e0117515. doi: 10.1371/journal.pone.0117515

Bluthgen, N., and Legewie, S. (2008). Systems analysis of MAPK signal transduction. Essay Biochem. 45, 95-107. doi: 10.1042/bse045095

Bluthgen, N., van Bentum, M., Merz, B., Kuhl, D., and Hermey, G. (2017). Profiling the MAPK.ERK dependent and independent activity regulated transcriptional programs in the murine hippocampus in vivo. Sci. Rep. 7:45101. doi: $10.1038 /$ srep45101

Bouton, M. (1994). Conditioning, remembering, and forgetting. J. Exp. Psychol. Anim. Behav. Process. 20, 219-231. doi: 10.1037/0097-7403.20.3.219

Bouton, M., and Swarzentruber, D. (1991). Sources of relapse after extinction in Pavlovian and instrumental learning. Clin. Psychol. Rev. 11, 123-140. doi: 10.1016/0272-7358(91)90091-8 
Braham, C., and Messaoudi, E. (2005). BDNF function in adult synaptic plasticity: the synaptic consolidation hypothesis. Prog. Neurobiol. 76, 99-125. doi: 10.1016/j.pneurobio.2005.06.003

Brakeman, P., Lanahan, A., O’Brien, R., Roche, K., Barnes, C., Huganir, R., et al. (1997). Homer: a protein that selectively binds metabotropic glutamate receptors. Nature 386, 284-288. doi: 10.1038/386284a0

Bramham, C., and Wells, D. (2007). Dendritic mRNA transport, translation and function. Nat. Rev. Neurosci. 8, 776-789. doi: 10.1038/nr n2150

Bramham, C., Worley, P., Moore, M., and Guzowski, J. (2008). The immediate early gene arc/arg3.1: regulation, mechanisms, and function. J. Neurosci. 28, 11760-11767. doi: 10.1523/JNEUROSCI.3864-08.2008

Brannan, S., Liotti, M., Egan, G., Shade, R., Madden, L., Robillard, R., et al. (2001). Neuroimaging of cerebral activations and deactivations associated with hypercapnea and hunger of air. Proc. Natl. Acad. Sci. U.S.A. 98, 2029-2034. doi: 10.1073/pnas.98.4.2029

Brooks, D., Palmatier, M., Garcia, E., and Johnson, J. (1999). An extinction cue reduces spontaneous recovery of a conditioned taste aversion. Anim. Learn. Behav. 27, 77-88. doi: 10.3758/BF03199433

Brooks, J., Zambreanu, L., Godinez, A., Craig, A., and Tracey, I. (2005). Somatotopic organisation of the human insula to painful heat studied with high resolution functional imaging. Neuroimage 27, 201-209. doi: 10.1016/j.neuroimage.2005.03.041

Brozzoli, C., Dematte, M., Pavani, F., Frassinetti, F., and Farne, A. (2006). Neglect and extinction: within and between sensory modalities. Restor. Neurol. Neurosci. 24, 217-232.

Budd, D., Willars, G., McDonald, J., and Tobin, A. (2001). Phosphorylation of the Gq/11-coupled m3-muscarinic receptor is involved in receptor activation of the ERK-1/2 mitogen-activated protein kinase pathway. J. Biol. Chem. 276, 4581-4587. doi: 10.1074/jbc.M008827200

Bures, J., Bermudez-Rattoni, F., and Yamamoto, Y. (1998). Conditioned Taste Aversion: Memory of a Special Kind. Oxford, NY: Oxford University Press.

Buresova, O. (1978). Neocortical-amygdalar interaction in the conditioned taste aversion in rats. Act. Nerv. Super 20, 224-230.

Buresova, O., and Bures, J. (1979). Extinction of newly acquired conditioned taste aversion: effect of gustatory CS administered under anaesthesia. Behav. Process. 4, 323-339. doi: 10.1016/0376-6357(79)90017-2

Buresova, O., and Bures, J. (1980). Post-ingestion interference with brain function prevents attenuation of neophobia in rats. Behav. Brain Res. 1, 299-312. doi: 10.1016/0166-4328(80)90023-6

Bushara, K., Grafman, J., and Hallett, M. (2001). Neural correlates of auditoryvisual stimulus onset asynchrony detection. J. Neurosci. 21, 300-304.

Bushara, K., Hanakawa, T., Immisch, I., Toma, K., Kansaku, K., and Hallett, M. (2003). Neural correlates of cross-modal binding. Nat. Neurosci. 6, 190-195. doi: $10.1038 / \mathrm{nn} 993$

Butti, C., and Hof, P. (2010). The insular cortex: a comparative perspective. Brain Struct. Funct. 214, 744-493. doi: 10.1007/s00429-010-0264-y

Cahill, C., and MacGaugh, J. (1996). Modulation of memory storage. Curr. Opin. Neuobiol. 6, 237-242. doi: 10.1016/S0959-4388(96)80078-X

Carleton, A., Accolla, R., and Simon, S. (2010). Coding in the mammalian gustatory system. Trends Neurosci. 33, 326-334. doi: 10.1016/j.tins.2010. 04.002

Carroll, M., Dinc, H., Levy, C., and Smith, J. (1975). Demonstrations of neophobia and enhanced neophobia in the albino rat. J. Comp. Physiol. Psychol. 89, 457-467. doi: 10.1037/h0077041

Casamenti, F., Deffenu, G., Abbamondt, A., and Pepeu, G. (1986). Changes in cortical acetylcholine output induced by modulation of neucleus basalis. Brain Res. Bull. 16, 689-695. doi: 10.1016/0361-9230(86)90140-1

Castillo, D., Figueroa-Guzman, Y., and Escobar, M. (2006). Brain-derived neurotrophic factor enhances conditioned taste aversion retention. Brain Res. 1067, 250-255. doi: 10.1016/j.brainres.2005.10.085

Chao, M. (2003). Neurotrophins and their receptors: a convergence point for many signalling pathways. Nat. Rev. Neurosci. 4, 299-309. doi: 10.1038/nrn1078

Chandrashekar, J., Kuhn, C., Oka, Y., Yarmolinsky, D. A., Hummler, E., Ryba, N. J. P., et al. (2010). The cells and peripheral representation of sodium taste in mice. Nature 464, 297-301. doi: 10.1038/nature08783

Chen, A., Hu, W., Jiang, X., Potegal, M., and Li, H. (2017). Molecular mechanisms of group I metabotropic glutamate receptor mediated LTP and
LTD in basolateral amygdala in vitro. Psychopharmacology 234, 681-694. doi: $10.1007 / \mathrm{s} 00213-016-4503-7$

Chen, J., Carta, S., Soldado-Magraner, J., Schneider, B., and Helmchen, F. (2013). Behaviour-dependent recruitment of long-range projection neurons in somatosensory cortex. Nature 499, 336-340. doi: 10.1038/nature 12236

Chen, X., Gabito, M., Peng, Y., Ryba, N., and Charlse, Z. C. (2011). A gustotopic map of taste qualities in the mammalian brain. Science 333, 1262-1266. doi: $10.1126 /$ science. 1204076

Chester, J., and Cunningham, C. (1999). Baclofen alters ethanol-stimulated activity but not conditioned place preference or taste aversion in mice. Pharmacol. Biochem. Behav. 63, 325-331. doi: 10.1016/S0091-3057(98)00253-6

Chowdhury, S., Shepherd, J., Okuno, H., Lyford, G., Petralia, R., Plath, N., et al. (2006). Arc/Arg3.1 interacts with the endocytic machinery to regulate AMP receptor trafficking. Neuron 52, 445-459. doi: 10.1016/j.neuron.2006.08.033

Chu, D., Albin, R., Young, A., and Penney, J. (1990). Distribution and kinetics of GABAB binding site in rat central nervous system: a quantitative autoradiographic study. Neuroscience 34, 341-357. doi: 10.1016/0306-4522(90)90144-S

Clarke, P. (1993). "Nicotinic receptors in mammalian brain: localization and relation to cholinergin innervation," in Progress in Brain Research, ed A. Cuello (Amsterdam: Elsevier), 77-83.

Concha, M., Bianco, I., and Wilson, S. (2012). Encoding asymmetry within neural circuits. Nat. Rev. Neurosci. 13, 832-843. doi: 10.1038/nrn3371

Costa-Mattioli, M., Gobert, D., Harding, H., Herdy, B., Azzi, M., Bruno, M., et al. (2005). Translational control of hippocamapl synaptic plasticity and memory by the eIF2a kinase GCN2. Nature 436, 1166-1173. doi: 10.1038/nature03897

Couey, J., Meredith, R., Spijker, S., Poorthuis, R., Smit, A., Brussaard, A., et al. (2007). Distributed network actions by nicotine increase the threshold for spike-timing-dependent plasticity in prefrontal cortex. Neuron 54, 73-87. doi: 10.1016/j.neuron.2007.03.006

Cousins, S., Papadakis, M., Rutter, A., and Stephenson, F. (2008). Differential interaction of NMDAR receptor subtypes with the post-synaptic denisty-95 family of membrane associated guanylate kinase proteins. J. Neurochem. 104, 903-913. doi: 10.1111/j.1471-4159.2007.05067.x

Craig, A. (1996). An ascending general homeostatic afferent pathway originating from lamina I. Prog. Brain Res. 107, 225-242. doi: 10.1016/S0079-6123(08)61867-1

Craig, A. (2002). How do you feel? Interoception: the sens of physiological condition of the body. Nat. Rev. Neurosci. 3, 655-666. doi: 10.1038/ nrn894

Craig, A. (2003). Interoception: the sense of the physiological condition of the body. Curr. Opin. Neurobiol. 13, 500-505. doi: 10.1016/S0959-4388(03)00090-4

Craig, A. (2009). How do you feel-now? The anterior insula and human awareness. Nat. Rev. Neurosci. 10, 59-70. doi: 10.1038/nrn2555

Craig, A., Chen, K., Bandy, D., and Reiman, E. (2000). Thermosensory activation of insular cortex. Nat. Neurosci. 3, 184-190. doi: 10.1038/72131

Critchley, H., and Seth, A. (2012). Will studies of macque insula reveal the neural mechanisms of self-awareness? Neuron 74, 423-426. doi: 10.1016/j.neuron.2012.04.012

Critchley, H., Wiens, S., Rotschtein, P., Ohman, A., and Dolan, R. (2005). Neural systems supporting interoceptive awareness. Nat. Neurosci. 7, 189-195. doi: $10.1038 / \mathrm{nn} 1176$

Dalenberg, J., Hoogeven, H., Renken, R., Langers, D., and ter Horst, G. (2015). Functional specialization of the male insula during taste perception. Neuroimage 119, 210-220. doi: 10.1016/j.neuroimage.2015.06.062

Damasio, A. (2003). Feelings of emotion and the self. Ann. N.Y. Acad. Sci. 1001, 253-261. doi: 10.1196/annals.1279.014

Damasio, A., Damasio, H., and Tranel, D. (2013). Persistence of feelings and sentience after bilateral damage of the insula. Cereb. Cortex 23, 833-846. doi: 10.1093/cercor/bhs077

Darwin, C. (1859). The Origin of Species. London: John Murray.

David, O., Barrera, I., Adaikkan, C., Kaphzan, H., Nakazawa, T., Yamamoto, T., et al. (2014). Dopamine-induced tyrosine phosphorylation of NR2B (Tyr1472) is essential for ERK1/2 activation and processing of novel taste information. Front. Mol. Neurosci. 7:66. doi: 10.3389/fnmol.2014.00066

Davis, H., and Squire, L. (1984). Protein synthesis and memory. A review. Psychol. Bull. 96, 518-559. doi: 10.1037/0033-2909.96.3.518 
Davis, S., and Laroche, S. (2006). Mitogen-activated protein kinase/extracellular regulated kinase signalling and memory stabilization: a review. Genes Brain Behav. 5, 61-72. doi: 10.1111/j.1601-183X.2006.00230.x

Davis, S., Butcher, S., and Morris, R. (1992). The NMDA receptor antagonist D2amino-5phosphopentanoate (D-AP5) impairs spatial learning and LTP in vivo at intracerebral concentrations comparable to those that block LTP in vitro. J. Neurosci. 12, 21-34.

de Araujo, I., and Simon, S. (2009). The gustatory cortex and multisensory integration. Int. J. Obes. 33, S34-S43. doi: 10.1038/ijo.2009.70

de Araujo, I., Oliveira-Maia, A., Sotnikova, T., Gainetdinov, R., Caron, M., Nicolelis, M., et al. (2008). Food reward in the absence of taste receptor signaling. Neuron 57, 930-941. doi: 10.1016/j.neuron.2008.01.032

De la Casa, G., and Lubow, R. (1995). Latent inhibition in conditioned taste aversion: the role of stimulus frequency and duration and the amount of fluid ingested during preexposure. Neurobiol. Learn. Mem. 64, 125-132. doi: 10.1006/nlme.1995.1051

Delmas, P., and Brown, D. (2005). Pathways modulating neural KCNQ/M(Kv7) potassium channels. Nat. Rev. Neurosci. 6, 850-862. doi: 10.1038/nrn1785

Desmedt, A., Hazvi, S., and Dudai, Y. (2003). Differential pattern of cAMP response element-binding protein activation in the rat brain after conditioned aversion as a function of the associative process engaged: taste versus context association. J. Neurosci. 23, 6102-6110.

DeSousa, N., Beinger, R., Jhamandas, K., and Boegman, R. (1994). Stimulation of GABAB receptors in the basal forebrain selectively impairs working memory in rats in double Y-maze. Brain Res. 641, 29-38. doi: 10.1016/0006-8993(94)91811-2

Deutsch, R. (1978). Effects of atropine on conditioned taste aversion. Pharmacol. Biochem. Behav. 8, 685-694. doi: 10.1016/0091-3057(78)90267-8

Doron, G., and Rosenblum, K. (2010). c-Fos expression is elevated in GABAergic interneurons of the gustatory cortex following novel taste learning. Neurobiol. Learn. Mem. 94, 21-29. doi: 10.1016/j.nlm.2010.03.003

Dong, Y. N., Waxman, E. A., and Lynch, D. R. (2004). Interactions of postsynaptic density-95 and the NMDA receptor 2 subunit control calpainmediated cleavage of the NMDA receptor. J. Neurosci. 24, 11035-11045. doi: 10.1523/JNEUROSCI.3722-04.2004

Dosenbach, N., Fair, D., Miezin, F., Cohen, A., Wnger, K., Dosenbach, R., et al. (2007). Distinct brain networks for adaptive and stable task control in humans. Proc. Natl. Acad. Sci. U.S.A. 104, 11073-11078. doi: 10.1073/pnas.0704320104

Driver, J., and Noesselt, T. (2009). Multisensory interplay reveals crossmodal influences on "sensory-specific" brain regions, neural responses, and judgments. Neuron 57, 11-23. doi: 10.1016/j.neuron.2007.12.013

Dudai, Y., and Eisenberg, M. (2004). Rite of passage of the engram: reconsolidation and the lingering consolidation hypothesis. Neuron 44, 93-100. doi: 10.1016/j.neuron.2004.09.003

Dudchenko, P., and Sarter, M. (1991). GABAergic control of basal forebrain cholinergic neurons and memory. Behav. Brain Res. 42, 33-41. doi: 10.1016/S0166-4328(05)80037-3

Dunn, L., and Everitt, B. (1988). Double dissociations of the effects of amygdala and insular cortex lesions on conditioned taste aversion, passive avoidance, and neophobia in the rat using the excitotoxin ibotenic acid. Behav. Neurosci. 102, 3-23. doi: 10.1037/0735-7044.102.1.3

Dunnet, S. (1993). The role and repair of forebrain cholinergic systems in shortterm memory. Studies using the delayed matching-to-position task in rats. Adv. Neurol. 59, 53-65.

Dunnet, S., Everitt, B., and Robbins, T. (1991). The basal forebrain-cortical cholinergic system: interpreting the functional consequences of excitotoxic lesions. Trends Neurosci. 14, 494-501. doi: 10.1016/0166-2236(91)90061-X

Ebbinghaus, H. (1964). Memory: A Contribution to Experimental Psychology. Dover, NY: Teacher College Columbia University.

Eisenberg, M., Kobilo, T., Berman, D., and Dudai, Y. (2003). Stability of retrieved memory: inverse correlation with trace dominance. Science 301, 1102-1104. doi: 10.1126/science.1086881

Elkobi, A., Ehrlich, I., Belelovsky, K., Barki-Harrington, L., and Rosenblum, K. (2008). ERK-dependent PSD-95 induction in the gustatory cortex is necessary for taste learning, but not retrieval. Nat. Neurosci. 11, 1149-1151. doi: 10.1038/nn.2190

Escobar, M., Alcocer, I., and Bermudez-Rattoni, F. (2002). In vivo effects of intracortical administration of NMDAR and metabotropic glutamate receptors antagonists on neocortical long-term potentiation and conditioned taste aversion. Behav. Brain Res. 129, 101-106. doi: 10.1016/S0166-4328(01)00329-1

Escobar, M., and Alcocer, I. C. (1998). The NMDA receptor antagonist CPP impairs conditioned taste aversion and insular cortex long term potentiation in vivo. Brain Res. 812, 246-251. doi: 10.1016/S0006-8993(98)00931-7

Escobar, M., and Bermudez-Rattoni, F. (2000). Long-term potentiation in the insular cortex enhances conditioned taste aversion retention. Brain Res. 852, 208-212. doi: 10.1016/S0006-8993(99)02134-4

Escobar, M., Chao, V., and Bermudez-Rattoni, F. (1997). In vivo long-term potentiation in the insular cortex: NMDA receptor dependence. Brain Res. 779, 314-319. doi: 10.1016/S0006-8993(97)01175-X

Escobar, M., Figueroa-Guzman, Y., and Gomez-Palacio-Schjetnan, A. (2003). In vivo insular cortex LTP induced by brain-derived neurotrophic factor. Brain Res. 991, 274-279. doi: 10.1016/j.brainres.2003.08.015

Everitt, B., and Robbins, T. (1997). Central cholinergic systems and cognition. Ann. Rev. Psychol. 48, 649-684. doi: 10.1146/annurev.psych.48.1.649

Fanselow, E., Richardson, K., and Connors, B. (2008). Selective, state-dependent activation of somatostatin-expressing inhibitory interneurons in mouse neocortex. J. Neurophysiol. 100, 2640-2652. doi: 10.1152/jn.90691.2008

Faurion, A., Cerf, B., Van De Moortele, P., Lobel, E., Mac Leod, P., and Le Bihan, D. (1999). Human taste cortical areas studied with functional magnetic resonance imaging: evidence of functional lateralization related to handedness. Neurosci. Lett. 277, 189-192. doi: 10.1016/S0304-3940(99)00881-2

Ferezou, I., Cauli, B., Hill, E., Rossier, J., Hamel, E., and Lambolez, B. (2002). 5-HT3 receptors mediate serotonergic fast synaptic excitation of neocortical vasoactive interstinal peptide/cholecystokinin interneurons. J. Neurosci. 22, 7389-7397.

Ferreira, G., Gutiérrez, R., De la Cruz, V., and Bermudez-Rattoni, F. (2002). Differential involvement of cortical muscarinic and NMDA receptors in shortand long-term tase aversion memory. Eur. J. Neurosci. 52, 91-97.

Ferreira, G., Miranda, M., De la Cruz, V., Rodriguez-Ortiz, C., and BermudezRattoni, F. (2005). Basolateral amygdala glutamatergic activation enhances taste aversion through NMDA receptor activation in the insular cortex. Eur. J. Neurosci. 22, 2596-2604. doi: 10.1111/j.1460-9568.2005.04440.x

Finkbeiner, S., Tavazoie, S., Maloratsky, A., Jacobs, K., Harris, K., and Greenberg, M. (1997). CREB: a major mediator of neuronal neurotrophin responses. Neuron 19, 1031-1047. doi: 10.1016/S0896-6273(00)80395-5

Fletcher, M., Ogg, C., Lu, L., Ogg, R., and Boughter, J. (2017). Overlapping representation of primary tastes in a defined region of the gustatory cortex. $J$. Neurosci. 37, 7595-7605. doi: 10.1523/JNEUROSCI.0649-17.2017

Fontanini, A., Grossman, S., Figueroa, J., and Katz, D. (2009). Distinct subtypes of basolateral amygdala taste neurons reflect palatability and reward. J. Neurosci. 29, 2486-2495. doi: 10.1523/JNEUROSCI.3898-08.2009

Fowler, S., Ramsey, A., Walker, J., Serfozo, P., Olive, M., Schachtman, T., et al. (2011). Functional interaction of mGlu5 and NMDA receptors in aversive learning in rats. Neurobiol. Learn. Mem. 95, 73-79. doi: 10.1016/j.nlm.2010.11.009

Fuehrlein, B., Ralevski, E., O’Brien, E., Jane, J., Arias, A., and Petrakis, I. (2014). Characteristics and drinking patterns of veterans with alcohol dependence with and without post-traumatic stress disorder. Addict. Behav. 39, 374-378. doi: 10.1016/j.addbeh.2013.08.026

Fujita, S., Adachi, K., Koshikawa, N., and Kobayashi, M. (2010). Spatiotemporal dynamics of excitation in rat insular cortex: intrinsic corticocortical circuit regulates caudal-rostro excitatory propagation from the insular to frontal cortex. Neuroscience 165, 278-292. doi: 10.1016/j.neuroscience.2009.09.073

Furini, C., Myskiw, J., and Izquierdo, I. (2014). The learning of fear extinction. Neurosci. Biobehav. Rev. 47, 670-683. doi: 10.1016/j.neubiorev.2014.10.016

Galati, G., Committeri, G., Sanes, J., and Pizzamiglio, L. (2001). Spatial coding of visual and somatic sensory information in body-centred coordinates. Eur. J. Neurosci. 14, 737-746. doi: 10.1046/j.0953-816x.2001.01674.x

Gal-Ben-Ari, S., and Rosenblum, K. (2012). Molecular mechanisms underlying memory consolidation of taste information in the cortex. Front. Behav. Neurosci. 5:87. doi: 10.3389/fnbeh.2011.00087

Gallo, M., Roldan, G., and Bures, J. (1992). Differential involvement of gustatory insular cortex and amygdala in the acquisition and retrieval of conditioned taste aversion in rats. Behav. Brain Res. 52, 91-97. doi: 10.1016/S0166-4328(05)80328-6

Garcia, J., Ervin, F., and Koelling, R. (1966). Learning with prolonged delay of reinforcement. Psychon. Sci. 5, 121-122. doi: 10.3758/BF03328311 
Gardner, M., and Fontanini, A. (2014). Encoding and tracking of outcome-specific expectancy in the gustatory cortex of alert rats. J. Neurosci. 34, 13000-13017. doi: 10.1523/JNEUROSCI.1820-14.2014

Garner, C., Nash, J., and Huganir, R. (2000). PDZ domains in synapse assembly and signalling. Trends Cell Biol. 10, 247-280. doi: 10.1016/S0962-8924(00)01783-9

Ghazanfar, A., and Schroeder, C. (2006). Is neocortex essentially multisensory? Trends Cogn. Sci. 10, 278-285. doi: 10.1016/j.tics.2006.04.008

Gil, Z., Connors, B., and Amitai, Y. (1997). Differential regulation of neocortical synapses by neuromodulators and activity. Neuron 19, 679-686. doi: $10.1016 /$ S0896-6273(00)80380-3

Giovannini, M., Camili, F., Mundula, A., Bianchi, L., Colivicchi, M., and Pepeu, G. (1995). Differential regulation by N-methyl-D-aspartate and non-N-methyl$\mathrm{D}$-aspartate receptors of acetylcholine release from the rat striatum in vivo. Neuroscience 65, 409-415. doi: 10.1016/0306-4522(94)00503-W

Gogolla, N., Takesian, A., Feng, G., Fagiolini, M., and Hensch, T. (2014). Sensory integration in mouse insular cortex reflects GABA circuit maturation. Neuron 83, 894-905. doi: 10.1016/j.neuron.2014.06.033

Gonzalez, M., Villar, M., I. L., Viola, H., and Medina, J. (2015). Dorsal medial prefrontal cortex contributes to conditioned taste aversion memory consolidation and retrieval. Neurobiol. Learn. Mem. 126, 1-6. doi: $10.1016 /$ j.nlm.2015.10.007

Grabenhorst, F., and Rolls, E. (2008). Selective attention to affective value alters how the brain processes taste stimuli. Eur. J. Neurosci. 27, 723-729. doi: $10.1111 / j .1460-9568.2008 .06033 . x$

Grabenhorst, F., Rolls, E., and Bilderbeck, A. (2008). How cognition modulates affective responses to taste and flavor: top-down influences on the orbitofrontal and pregenual cingulate cortices. Cereb. Cortex 18, 1549-1559. doi: 10.1093/cercor/bhm185

Grossman, S. E., Fontanini, A., Wieskopf, J. S., and Katz, D. B. (2008). Learning-related plasticity of temporal coding in simultaneously recorded amygdala-cortical ensembles. J. Neurosci, 28, 2864-2873. doi: 10.1523/JNEUROSCI.4063-07.2008

Guzowski, J. F., McNaughton, B., Barnes, C., and Worley, P. (2001). Imaging neural activity with temporal and cellular resolution using FISH. Curr. Opin. Neurobiol. 11, 579-584. doi: 10.1016/S0959-4388(00) 00252-X

Gutiérrez, R., Rodriguez-Ortiz, C., De la Cruz, V., Núñez-Jaramillo, L., and Bermudez-Rattoni, F. (2003b). Cholinergic dependence of taste memory formation: evidence of two distinct processes. Neurobiol. Learn. Mem. 80, 323-331. doi: 10.1016/S1074-7427(03)00066-2

Gulledge, A., Park, S., Kawaguchi, Y., and Stuart, G. (2007). Heterogeneity of phasic cholinergic signaling in neocortical neurons. J. Neurophysiol. 97, 2215-2229. doi: 10.1152/jn.00493.2006

Gutiérrez, H., Gutiérrez, R., Ramirez-Trejo, L., Silva-Gandarias, R., Ormsby, C., Miranda, M., et al. (1999c). Redundant basal forebrain modulation in taste aversion memory formation. J. Neurosci. 19, 7661-7669.

Gutiérrez, H., Gutiérrez, R., Silva-Gandarias, R., Estrada, J., Miranda, M., and Bermudez-Rattoni, F. (1999b). Differential effects of 192IgG-saporin and NMDA-induced lesions into the basal forebrain on cholinergic activity and taste aversion memory formation. Brain Res. 834, 136-141.

Gutiérrez, H., Hernandez-Echeagaray, E., Ramirez-Amaya, V., and BermudezRattoni, F. (1999a). Blockade of N-methyl-D-aspartate receptors in the insular cortex disrupts taste aversion and spatial memory formation. Neuroscience 89 751-758. doi: 10.1016/S0306-4522(98)00360-1

Gutiérrez, R., Simon, S., and Nicolelis, M. (2010). Licking-induced synchrony in the taste-reward circuit improves cue discrimination during learning. J. Neurosci. 30, 287-303. doi: 10.1523/JNEUROSCI.085509.2010

Gutiérrez, R., Tellez, L., and Bermudez-Rattoni, F. (2003a). Blockade of cortical muscarinic but not NMDA receptors prevents a novel taste from becoming familiar. Eur. J. Neurosci. 17, 1556-1562. doi: 10.1046/j.1460-9568.2003. 02608.x

Guzman-Ramos, K., and Bermudez-Rattoni, F. (2012). Interplay of amygdala and insular cortex during and after associative taste aversion memory formation. Rev. Neurosci. 23, 463-471. doi: 10.1515/revneuro-2012-0056

Guzman-Ramos, K., Osorio-Gomez, D., Moreno-Castilla, P., and BermudezRattoni, F. (2010). Off-line concomitant release of dopamine and glutamate involvement in taste memory consolidation. J. Neurochem. 114, 226-236. doi: 10.1111/j.1471-4159.2010.06758.x
Guzman-Ramos, K., Osorio-Gómez, D., Moreno-Castilla, P., and BermúdezRattoni, F. (2012). Post-acquisition release of glutamate and norepinephrine in the amygdala is involved in taste-aversion memory consolidation. Learn. Mem. 19, 231-238. doi: 10.1101/lm.024703.111

Guzowski, J., and Worley, P. (2001). Cellular compartment analysis of temporal activity by fluorescence in situ hybridization (catFISH). Curr. Protoc. Neurosci. Chapter 1, Unit 1.8. doi: 10.1002/0471142301.ns0108s15

Guzowski, J., Lyford, G., Stevenson, G., Houston, F., McGaugh, J., Worely, P., et al. (2000). Inhibition of activity-dependent arc protein expression in the rat hippocampus impairs the maintenance of long-term potentiation and consolidation of long-term memory. J. Neurosci. 20, 3993-4001.

Guzowski, J., McNaughton, B., Barnes, C., and Worley, P. (1999). Environmentspecific expression of the immediate-early gene Arc in hippocampal neuronal ensembles. Nat. Neurosci. 2, 1120-1124. doi: 10.1038/16046

Haley, M., Fontanini, A., and Maffei, A. (2016). Laminar- and Target-specific amygdalar inputs in rats primary gustatory cortex. J. Neurosci. 36, 2623-2637. doi: 10.1523/JNEUROSCI.3224-15.2016

Hall, G. (1991). Perceptual and Associative Learning. Oxford Psychology Series No. 18 Edn. Oxford: Carendon Press.

Hall, G., and Channell, S. (1985). Differential effects of contextual change on latent inhibition and on the habituation of an orienting response. J. Exp. Psychol. 11, 470-481. doi: 10.1037/0097-7403.11.3.470

Hall, G., and Pearce, J. (1979). Latent inhibition of a CS during CS-US pairings. J. Exp. Psychol. 5, 31-41. doi: 10.1037/0097-7403.5.1.31

Halpern, M., Gunturkun, O., Hopkins, W., and Rogers, L. (2005). Lateralization of the vertebrate brain: taking the side of model systems. J. Neurosci. 25, 10351-10357. doi: 10.1523/JNEUROSCI.3439-05.2005

Hashikawa, K., Naka, M., Nakayama, D., Matsumonoto, N., Neve, R., and Matsuki, N. (2013). Blockade of stimulus converge in amygdala neurons disrupts taste associative learning. J. Neurosci. 33, 4958-4963. doi: 10.1523/JNEUROSCI.5462-12.2013

Hashimoto, K., and Spector, A. (2014). Extensive lesions in the gustatory cortex in the rat do not disrupt the retention of a presurgically conditioned taste aversion and do not impair unconditioned concentration-dependent licking of sucrose and quinine. Chem. Senses 39, 57-71. doi: 10.1093/chemse/bjt054

Hasselmo, M., and Giocomo, L. (2006). Cholinergic modulation of cortical function. J. Mol. Neurosci. 30, 133-135. doi: 10.1385/JMN:30:1:133

Hasselmo, M., and McGaughy, J. (2004). High acetylcholine sets circuit dynamics for attention and encoding; low acetylcholine sets dynamics for consolidation. Prog. Brain Res. 145, 207-231. doi: 10.1016/S0079-6123(03)45015-2

Henneberger, C., Juttner, R., Rother, T., and Grantyn, R. (2002). Postsynaptic action of BDNF on GABAergic synaptic transmission in the superficial layers of the mosue superior colliculus. J. Neurophys. 88, 595-603. doi: 10.1152/jn.00673.2001

Himmelheber, A., Sarter, M., and Bruno, J. (2001). The effects of manipulations of attentional demand on cortical acetylcholine release. Brain Res. Cogn. Brain Res. 12, 353-370. doi: 10.1016/S0926-6410(01)00064-7

Hipskind, R., Rao, V., Mueller, C., Reddy, E., and Nordheim, A. (1991). Ets-related protein Elk-1 is homologous to the c-fos regulatory factor p62TCF. Nature 354, 531-534. doi: 10.1038/354531a0

Holca-Lamarre, R., Lucke, J., and Obermayer, K. (2017). Models of Acetylcholine and Dopamine signals differentially improve neural representations. Front. Comput. Neurosci. 11:54. doi: 10.3389/fncom.2017.00054

Huang, A., Chen, X., Hoon, M., Chandrashekar, J., Guo, W., Tranker, D., et al. (2006). The cells and logic for mammalian sour taste detection. Nature 442, 934-938. doi: 10.1038/nature05084

Huang, E., and Reichardt, L. (2001). Neurotrophins: roles in neuronal development and function. Annu. Rev. Neurosci. 24, 677-736. doi: 10.1146/annurev.neuro.24.1.677

Huang, F., Chotiner, J., and Steward, O. (2007). Actin polymerization and ERK phosphorylation are required for Arc/Arg3.1 mRNA targeting to activated synaptic sites on dendrites. J. Neurosci. 27, 9054-9067. doi: 10.1523/JNEUROSCI.2410-07.2007

Ibanez, A., Gleichgerrcht, E., and Manes, F. (2010). Clinical effects of insular damage in humans. Brain Struct. Funct. 214, 397-410. doi: 10.1007/s00429-010-0256-y

Im, B., and Rhim, H. (2012). GABA(B) receptor-mediated ERK1/2 phosphorylation via direct interaction with $\mathrm{CA}(\mathrm{V}) 1.3$ channels. Neurosci. Lett. 513, 89-94. doi: 10.1016/j.neulet.2012.02.014 
Inberg, S., Elkobi, A., Edri, E., and Rosenblum, K. (2013). Taste familiarity is inversely correlated with Arc/Arg3.1 hemispheric lateralization. J. Neurosci. 33, 11734-11743. doi: 10.1523/JNEUROSCI.0801-13.2013

Inberg, S., Jacob, E., Elkobi, A., Edry, E., Rappaport, A., Simpson, I., et al. (2016). Fluid consumption and taste novelty determines transcription temporal dynamics in the gustatory cortex. Mol. Brain 9:13. doi: 10.1186/s13041-016-0188-4

Isnard, J., Guenot, M., Sindou, M., and Mauguiere, F. (2004). Clinical manifestations of insular lobe seizures: a stereo-electroencephalographic study. Epilepsia 45, 1079-1090. doi: 10.1111/j.0013-9580.2004.68903.x

Iwasaki, Y., Gay, B., Wada, K., and Koizumi, S. (1998). Association of the Src family tyrosine kinase Fyn with TrkB. J. Neurochem. 71, 106-111. doi: 10.1046/j.1471-4159.1998.71010106.x

Jacobson, L., Kelly, P., Bettler, B., Kaupmann, K., and Cryan, J. (2006). $\mathrm{GABAB}(1)$ receptor isoforms differentially mediate the acquisition and extinction of aversive taste memories. J. Neurosci. 26, 8800-8803. doi: 10.1523/JNEUROSCI.2076-06.2006

Jakkamstti, V., Tsai, N.-P., Gross, C., Molinaro, G., Collins, K., Nicoletti, F., et al. (2013). Experience-induced Arc/Arg3.1 primes CA1 pyramidal neurons for mGluR-dependent long-term synaptic depression. Neuron 80, 72-79. doi: 10.1016/j.neuron.2013.07.020

James, W. (1884). What is an emotion? Mind 9, 288-205.

Jasmin, L., Burkey, A., Granato, A., and Ohara, P. (2004). Rostral agranular insular cortex and pain areas of the central nervous system: a tract-tracing study in the rat. J. Comp. Neurol. 468, 425-440. doi: 10.1002/cne.10978

Jezzini, A., Mazzucato, L., La Camera, G., and Fontanini, A. (2013). Processing of hedonic and chemosensory features of taste in medial prefrontal and insular networks. J. Neurosci. 33, 18966-18978. doi: 10.1523/JNEUROSCI.2974-13.2013

Joels, G., and Lamprecht, R. (2014). Fear memory formation can affect a different memory: fear conditioning affects the extinction, but not retrieval, of conditioned taste aversion (CTA) memory. Front. Behav. Neurosci. 8:324. doi: $10.3389 /$ fnbeh.2014.00324

Jones, L. F., and Katz, D. (2006). Gustatory processing: a dynamic systems approach. Curr. Opin. Neurobiol. 16, 420-428. doi: 10.1016/j.conb.2006.06.011

Jones, L., Fontanini, A., Sadacca, B., Miller, P., and Katz, D. (2007). Natural stimuli evoke dynamic sequences of states in sensory cortical ensembles. Proc. Natl. Acad. Sci. U.S.A. 104, 18772-18777. doi: 10.1073/pnas.07055 46104

Jones, M., French, P., Bliss, T., and Rosenblum, K. (1999). Molecular mechanisms of long-term potentiation in the insular cortex in vivo. J. Neurosci. 19, RC36.

Kandel, E. (2001). The molecular biology of memory storage: a dialogue between genes and synapses. Science 294, 1030-1038. doi: 10.1126/science.1067020

Kandel, E. (2012). The molecular biology of memory: cAMP, PKA, CRE, CREB-1, CREB-2 and CPEB. Mol. Brain 5:14. doi: 10.1186/1756-6606-5-14

Kanhema, T., Dagestad, G., Panja, D., Tiron, A., Messaoudi, E., Havik, B., et al. (2006). Dual regulation of translation initiation and peptide chain elongation during BDNF-induced LTP in vivo: evidence of compartment-specific translation control. J. Neurochem. 19, 1328-1337. doi: $10.1111 /$ j.1471-4159.2006.04158.x

Katz, D., Simon, S., and Nicolelis, M. (2001). Dynamic and multimodal responses of gustatory cortical neurons in awake rats. J. Neurosci. 21, 4478-4489.

Katz, D., Simon, S., and Nicolelis, M. (2002). Taste-specific neuronal ensembles in the gustatory cortex of awake rats. J. Neurosci. 22, 1850-1857.

Katz, P., and Harris-Warrick, R. (1999). The evolution of neuronal circuits underlying species-specific behavior. Curr. Opin. Neurobiol. 9, 628-633. doi: 10.1016/S0959-4388(99)00012-4

Kawaguchi, Y., and Kubota, Y. (1997). GABAergic cell subtypes and their synaptic connections in rat frontal cortex. Cereb. Cortex 7, 476-486. doi: 10.1093/cercor/7.6.476

Kaye, H., and Pearce, J. (1984). The strength of the orienting response during Pavlovian conditioning. J. Exp. Psychol. 10, 90-109. doi: $10.1037 / 0097-7403.10 .1 .90$

Kaye, H., and Pearce, J. (1987). Hippocampal lesions attenuate latent inhibition of a CS and a neutral stimulus. Q. J. Exp. Psychol. 39B, 107-125.

Kelly, M., and Deadwyler, S. (2002). Acquisition of a novel behavior induces higher levels of Arc mRNA than does overtrained performance. Neuroscience 110, 617-626. doi: 10.1016/S0306-4522(01)00605-4
Kelly, M., and Deadwyler, S. (2003). Experience-dependent regulation of the immediate-early gene arc differs across brain regions. J. Neurosci. 23, 6443-6451.

Kiefer, S., and Orr, M. (1992). Taste avoidance, but not aversion, learning in rats lacking gustatory cortex. Behav. Neurosci. 106, 140-146. doi: $10.1037 / 0735-7044.106 .1 .140$

Kim, J., Pignatelli, M., Xu, S., Itohara, S., and Tonegawa, S. (2016). Antagonistic negative and positive neurons of the basoalteral amygdala. Nat. Neurosci. 19, 1636-1651. doi: 10.1038/nn.4414

Kim, J., Yang, M., Oh, C., Kim, K., Ha, M., Kang, S., et al. (1999). Signalling pathway leading to an activation of mitogen-activated protein kinase by stimulating M3 muscarinic receptor. Biochem. J. 337(Pt 2), 275-280. doi: 10.1042/bj33 70275

Kim, J., Zhang, X., Muralidhar, S., LeBlanc, S., and Tonegawa, S. (2017). Basolateral to central amygdala neural circuits for appetitive behaviors. Neuron 93, 1464-1479. doi: 10.1016/j.neuron.2017.02.034

Kim, M., Mizumori, S., and Bernstein, I. (2010). Neuronal representation of conditioned taste in the basolateral amygdala of rats. Neurobiol. Learn. Mem. 93, 406-414. doi: 10.1016/j.nlm.2009.12.007

Kim, R., Okuno, H., and Bito, H. (2012). Deciphering the molecular rules governing synaptic targeting of memory-related protein Arc. Commun. Integr. Biol. 5, 496-498. doi: 10.4161/cib.20853

Kimura, F. (2000). Cholinergic modulation of cortical function: a hypothetical role in shifting the dynamics in cortical network. Neurosci. Res. 36, 19-26. doi: 10.1016/S0168-0102(00)00151-6

Kimura, F., Fukuda, M., and Tsumoto, T. (1999). Acetylcholine suppresses the spread of excitation in the visual cortex revealed by optical recording: possible differential effect depending on the source of input. Eur. J. Neurosci. 11, 3597-3609. doi: 10.1046/j.1460-9568.1999.00779.x

Kobayashi, M. (2006). Functional organization of the human gustatory cortex. J. Oral Biosci. 48, 244-260. doi: 10.1016/S1349-0079(06)80007-1

Koh, M., and Bernstein, I. (2005). Mapping conditioned taste aversion associations using c-Fos reveals a dynamic role for insular cortex. Behav. Neurosci. 119, 388-398. doi: 10.1037/0735-7044.119.2.388

Koh, M., Wheeler, D., and Gallagher, M. (2009). Hippocampal lesions interfere with long-trace taste aversion conditioning. Physiol. Behav. 98, 103-107. doi: 10.1016/j.physbeh.2009.04.017

Koh, M., Wilkins, E., and Bernstein, I. (2003). Novel tastes elevate c-fos expression in the central amygdala and insular cortex: implication for taste aversion learning. Behav. Neurosci. 117, 1416-1422. doi: 10.1037/0735-7044.117.6.1416

Kral, P. (1971). Effects of scopolamine injection during CS-US interval on conditioning. Psychol. Rep. 28:690. doi: 10.2466/pr0.1971.28.3.690

Krushel, L., and van der Kooy, D. (1988). Visceral cortex: integration of the mucosal sense with limbic information in the rat agranular insular cortex. J. Comp. Neurol. 270, 39-54. doi: 10.1002/cne.902700105

Kurth, F. (2010). A link between the systems: functional differentiation and integration within the human insula revealed by meta-analysis. Brain Struct. Funct. 214, 519-534. doi: 10.1007/s00429-010-0255-Z

Kutscher, C., and Wright, W. (1977). Unconditioned taste aversion to quinine induced by injections of $\mathrm{NaCl}$ and $\mathrm{NiCl}$ : dissociation of aversion from cellular dehydration. Physiol. Behav. 18, 87-94. doi: 10.1016/0031-9384(77)90098-1

Kutscher, C., Wright, W., and Lisch, M. (1977). NaCl and LiCl efficacy in the induction of aversion for quinine and saccharin solutions immediately following injection. Pharmacol. Biochem. Behav. 6, 567-569. doi: 10.1016/0091-3057(77)90118-6

Lavezzari, G., McCallum, J., Lee, R., and Roche, K. (2003). Differential binding of the AP-2 adaptor complex and PSD-95 to the C-terminus of the NMDA receptor subunit NR2B regulate surface expression. Neuropharmacology 45, 729-737. doi: 10.1016/S0028-3908(03)00308-3

Lee, P., Cohen, J., Becker, K., and Fields, R. (2005). Gene expression in the conversion of early-phase to late-phase long-term potentiation. Ann. N.Y. Acad. Sci. 1048, 259-271. doi: 10.1196/annals.1342.023

Lee, S., Kim, S., Kwon, O., Lee, J., and Kim, J. (2013). Inhibitory networks of the amygdala for emotional memory. Front. Neural Circ. 7:129. doi: $10.3389 /$ fncir.2013.00129

Leibrock, J., Lottspeich, F., Hohn, A., Hofer, M., and Hengerer, B. (1989). Molecular cloning and expression of brain-derived neurotrophic factor. Nature 341, 149-152. doi: $10.1038 / 341149 a 0$ 
Levitan, D., Gal-Ben-Ari, S., Heise, C., Rosenberg, T., Elkobi, A., Ingerg, S., et al. (2016). The differential role of cortical protein synthesis in taste memory formation and persistence. NPJ Sci. Learn. 1:16001. doi: $10.1038 /$ npjscilearn.2016.1

Lin, J., and Reilly, S. (2012). Amygdala-gustatory insular cortex connections and taste neophobia. Behav. Brain Res. 235, 182-188. doi: 10.1016/j.bbr.2012.07.040

Lin, J., Arthurs, J., and Reilly, S. (2015). Gustatory insular cortex, aversive taste memory and taste neophobia. Neurobiol. Learn. Mem. 119, 77-84. doi: 10.1016/j.nlm.2015.01.005

Link, W., Konietzko, U., Kauselmann, G., Krug, M., Schwanke, B., Frey, U., et al. (1995). Somatodendritic expression of an immediate early gene is regulated by synaptic activity. Proc. Natl. Acad. Sci. U.S.A. 92, 5734-5738. doi: $10.1073 /$ pnas.92.12.5734

Linnarsson, S., Bjorklund, A., and Ernfors, P. (1997). Learning deficit in BDNF mutant mice. Eur. J. Neurosci. 9, 2581-2587. doi: 10.1111/j.1460-9568.1997.tb01687.x

Lopez-Garcia, J., Fernandez-Ruiz, J., Escobar, M., Bermudez-Rattoni, F., and Tapia, R. (1993). Effects of excitotoxic lesions of the nuclues basalis magnocellularis on conditioned taste aversion and inhibitory avoidance in the rat. Pharmacol. Biochem. Behav. 45, 147-152. doi: 10.1016/0091-3057(93)90098-E

Lubow, R. (1973). Latent inhibition. Psychol. Bull. 79:398. doi: 10.1037/h0034425

Lubow, R. (1989). Latent Inhibition and Conditioned Attention Theory. Cambridge: Cambridge University Press.

Lust, J., Geuze, R., Groothuis, A., and Bouma, A. (2011). Functional cerebral lateralization and dual-task efficiency-testing the function of human brain lateralization using fTCD. Behav. Brain Res. 217, 293-301. doi: 10.1016/j.bbr.2010.10.029

Lyford, G., Yamagata, K., Kaufmann, W., Barnes, C., Sanders, L., Copeland, N., et al. (1995). Arc, a growth factor and activity-regulated gene, encodes a novel cytoskeleton-associated protein that is enriched in neuronal dendrites. Neuron 14, 433-445. doi: 10.1016/0896-6273(95)90299-6

Ma, L., Wang, D., Zhang, T., Yu, H., Wang, Y., Huang, S., et al. (2011). Region-specific involvement of BDNF secretion and synthesis in conditioned taste aversion memory formation. J. Neurosci. 31, 2079-2090. doi: 10.1523/JNEUROSCI.5348-10.2011

MacKintosh, N. (1975). A theory of attention: variations in the associability of stimulus with reinforcement. Psychol. Rev. 82, 276-298. doi: 10.1037/h0076778

Mackintosh, N. (1983). Conditioning and Associative Learning. Oxford: Oxford University Press.

Majchrzak, M., Brailowsky, S., and Will, B. (1990). Chronic infusion of GABA and saline into the nucleus basalis magnocellularis in rats II. Cognitive impairments. Behav. Brain Res. 37, 45-56. doi: 10.1016/0166-4328(90) 90071-L

Marotta, R., Fenu, S., Scheggi, S., Vinci, S., Rosas, M., Falqui, A., et al. (2014). Acquisition and expression of conditioned taste aversion diffentially affects etracellular signal regulated kinase and glutamate receptor phosphoyrlation in rat profrontal cortex and nucleus accumbens. Front. Behav. Neurosci. 8:153. doi: 10.3389/fnbeh.2014.00153

Maroun, M., Kavushansky, A., Holmes, A., Wellman, C., and Motanis, H. (2012). Enhanced extinction of aversive memories by high-frequency stimulation of the rat infralimbic cortex. PLoS ONE 7:e35853. doi: 10.1371/journal.pone.0035853

Martinez-Moreno, A., Rodrigeuz-Duran, L., and Escobar, M. (2016). Brain-derived neurotrophic factor into adult neocortex strengthens a taste aversion memory. Behav. Brain Res. 297, 1-4. doi: 10.1016/j.bbr.2015.09.034

McCasland, J., and Hibbard, L. (1997). GABAergic neurons in barrel cortex show strong, whisker-dependent metabolic activation during normal behavior. J. Neurosci. 17, 5509-5527.

McCormick, D., and Prince, D. (1985). Two types of muscarinic response to acetylcholine in mammalian cortical neurons. Proc. Natl. Acad. Sci. U.S.A. 82, 6344-6348. doi: 10.1073/pnas.82.18.6344

McCormick, D., and Prince, D. (1986). Acetylcholine induces burst firing in thalamic reticular neurons by activating a potassium conductance. Nature 319 , 402-405. doi: 10.1038/319402a0

McGaugh, J. (2000). Memory - a century of consolidation. Science 287, 248-251. doi: $10.1126 /$ science.287.5451.248

Melzer, P., and Steiner, H. (1997). Stimulus-dependent expression of immediateearly genes in rat somatosensory cortex. J. Comp. Neurol. 380, 145-153. doi: 10. 1002/(SICI)1096-9861(19970331)380:1\&lt;145::AID-CNE11\&gt;3.0.CO;2-Z
Merhav, M., Kuulmann-Vander, S., Elkobi, A., Jacobson-Pick, S., Karni, A., and Rosenblum, K. (2006). Behavioral intereference and C/EBP $\beta$ expression in the insular-cortex reveal a prolonged time period of taste memory consolidation. Learn. Mem. 13, 571-574. doi: 10.1101/lm.282406

Merhav, M., and Rosenblum, K. (2006). Facilitation of taste memory acquisition by experiencing previous novel taste in protein-synthesis dependent. Learn. Mem. 13, 571-574. doi: 10.1101/lm.986008

Messaoudi, E., Kanhema, T., Soule, J., Tiron, A., Dagyte, G., da Silva, B., et al. (2007). Sustained Arc/Arg3.1 synthesis controls longterm potentiation consolidation through regulation of local actin polymerization in the dentate gyrus in vivo. J. Neurosci. 27, 10445-10455. doi: 10.1523/JNEUROSCI.2883-07.2007

Mesulam, M., and Mufson, E. (1982a). Insula of the old world monkey. I. Architectonics in the insulo-orbito-temporal component of the paralimbic brain. J. Comp. Neurol. 212, 1-22. doi: 10.1002/cne.902120102

Mesulam, M., and Mufson, E. (1982b). Insula of the old world monkey. III: Afferents cortical input and comments on function. J. Comp. Neurol. 212, 38-52. doi: $10.1002 /$ cne.902120104

Mickley, G., Hoxha, Z., Bacik, S., Kenmuir, C., Wellman, J., Biada, J., et al. (2007). Spontaneous Recovery (SR) of a conditioned taste aversion (CTA) differentially alters Extinction-induced changes in c-fos protein expression in rat amygdala (AMY) and Neocortex. Brain Res. 1152, 139-157. doi: 10.1016/j.brainres.2007.03.050

Mickley, G., Kenmuir, C., Yocom, A., Wellman, J., and Biada, J. (2005). A role for prefrontal cortex in the extinction of a conditioned taste aversion. Brain Res. 1051, 176-182. doi: 10.1016/j.brainres.2005.05.033

Mickley, G., Wilson, G., Remus, J., Ramos, L., Ketchesin, K., Biesan, O., et al. (2011). Periaqueductal gray $\mathrm{c}$-fos expression varis relative to the method of conditioned taste aversion extinction employed. Brain Res. 1342, 17-29. doi: 10.1016/j.brainres.2011.09.033

Miguel-Gonzalez, M., Gomez-Palacio-Shjetnan, A., and Escobar, M. (2008). BFND revereses the CTA memory deficits produced by inhibition of protein synthesis. Neurobiol. Learn. Mem. 90, 584-587. doi: 10.1016/j.nlm.2008.06.003

Miller, S., Nonneman, A., Kelly, K., Neisewander, J., and Isaac, W. (1986). Disruption of neophobia, conditioned odor aversion, and conditioned taste aversion in rats with hippocampal lesions. Behav. Neural Biol. 45, 240-253. doi: 10.1016/S0163-1047(86)90816-2

Minichiello, L., Korte, M., Wolfer, D., Kuhn, R., Unsicker, K., Cestari, V., et al. (1999). Essential role of TrkB receptors in hippocampus-mediated learning. Neuron 24, 401-414. doi: 10.1016/S0896-6273(00)80853-3

Miranda, M., and Bermudez-Rattoni, F. (1999). Reversible inactivation of the nucleus basalis magnocellularis induces disruption of cortical acetylcholine release and acquisition, but not retrieval, of aversive memories. Proc. Natl. Acad. Sci. U.S.A. 96, 6478-6482. doi: 10.1073/pnas.96.11.6478

Miranda, M., and McGaugh, J. (2004). Enhancement of inhibitory avoidance and conditioned taste aversion memory with insular cortex infusions of 8-BrcAMP: involvement of the basolateral amygdala. Learn. Mem. 11, 312-317. doi: $10.1101 / \mathrm{lm} .72804$

Miranda, M., Ramirez-Lugo, L., and Bermudez-Rattoni, F. (2000). Cortical cholinergic activity is related to the novelty of the stimulus. Brain Res. 882 , 230-235. doi: 10.1016/S0926-6410(00)00050-1

Miyakawa, T., Yagi, T., Kitazawa, H., Yasuda, M., Kawai, N., Tsuboi, K., et al. (1997). Fyn-kinase as a determinant of ethanol sensitivity: relation to NMDA receptor function. Science 278, 698-701. doi: 10.1126/science.278.5338.698

Mizuno, M., Yamada, K., He, J., Nakajima, A., and Nabeshima, T. (2003). Involvement of BDNF receptor TrkB in spatial memory formation. Learn. Mem. 10, 108-115. doi: 10.1101/lm.56003

Moor, E., Schirm, E., Jacso, J., and Westerink, B. (1998). Involvement of medial septal glutamate and GABAA receptors in behaviour-induced acetylcholine release in the hippocampus: a dual probe microdialysis study. Brain Res. 789, 1-8. doi: 10.1016/S0006-8993(97)01445-5

Moraga-Amaro, R., Cortes-Rojas, A., Simon, F., and Stehberg, J. (2014). Role of the insular cortex in taste familiarity. Neurobiol. Learn. Mem. 109, 37-45. doi: 10.1016/j.nlm.2013.11.012

Morgan, M., and LeDoux, J. (1993). Differential contribution of dorsal and ventral medial prefronal cortex in the acquisition and extinction of conditioned fear in rats. Behav. Neurosci. 109, 681-688. doi: 10.1037/0735-7044.1 09.4.681 
Morin, J., Quiroz, C., Mendoza-Viveros, L., Ramirez-Amaya, V., and BermudezRattoni, F. (2011). Familiar taste induces higher dendritic levels of activityregualted cytoskeleton-associated protein in the insular cortex than a novel one. Learn. Mem. 18, 610-616. doi: 10.1101/lm.2323411

Moron, I., Ramirez, L., Ballesteros, M., Gutiérrez, R., Miranda, M., Gallo, M., et al. (2002). Differential effects of bicuculline and muscimol microinjection into the nucleus basalis magnocellularis in taste and place aversive memory formation. Behav. Brain Res. 134, 425-431. doi: 10.1016/S0166-4328(02) 00056-6

Mueller, K., Hoon, M., Erlenbach, I., Chandrashekar, J., Zuker, C., and Ryba, N. (2005). The receptors and coding logic for bitter taste. Nature 434, 225-229. doi: $10.1038 /$ nature 03352

Muir, J., Robbins, T., and Everitt, B. (1992). Disruptive effects of muscimol infused into the basal forebrain on conditional discrimination and visual attention: differential interactions with cholinergic mechanisms. Psychopharmacology 107, 541-550. doi: 10.1007/BF02245269

Muller, G., and Pilzecker, A. (1900). Experimentelle beitrage zur lehre von gedachtnis. Z. Psychol. 1, 1-300.

Murayama, M., Perez-Garci, E., Nevian, T., Bock, T., Senn, W., and Larkum, M. (2009). Dendritic encoding of sensory stimuli controlled by deep cortical interneurons. Nature 457, 1137-1141. doi: 10.1038/nature07663

Nachman, M. (1970). Learned taste and temperature aversion due to lithium chloride sickness after temporal delays. J. Comp. Physiol. Psychol. 73, 22-30. doi: 10.1037/h0029807

Naisbitt, S., Kim, E., Tu, C., Xiao, B., Sala, C., Valtschanoff, J., et al. (1999). Shank, a novel family of postsynaptic density proteins that binds to the NMDA receptor/PSD-95/GKAP complex and cortactin. Neuron 23, 569-582. doi: 10.1016/S0896-6273(00)80809-0

Naor, C., and Dudai, Y. (1996). Transient impairment of cholingergic function in the rat insular cortex disrupts the encoding of taste in conditioned taste aversion. Behav. Brain Res. 79, 61-67. doi: 10.1016/0166-4328(95)00262-6

Niijima, A., and Yamamoto, T. (1994). The effects of lithium chloride on the activity of the afferent nerve fibers from the abdominal visceral organs in the rat. Brain Res. Bull. 35, 141-145. doi: 10.1016/0361-9230(94)90094-9

Nikolaienko, O., Patil, S., Eriksen, M. S., and Bramham, C. R. (2017a). Arc protein: a flexible hub for synaptic plasticity and cognition. Semin. Cell Dev. Biol. S1084-S9521, 30343-30349. doi: 10.1016/j.semcdb.2017.09.006

Nikolaienko, O., Eriksen, M. S., Patil, S., Bito, H., and Bamham, C. R. (2017b). Stimulus-evoked ERK-dependent phosphoyrlation of activity-regulated cytoskeleton-associated protein (Arc) regulates its neuronal subcellular localization. Neuroscience 360, 68-80. doi: 10.1016/j.neuroscience.2017.07.026

Nunez-Jaramillo, L., Jimenez, B., Ramirez-Munguia, N., Delint-Ramirez, I., Luna-Illades, C., Tapia, R., et al. (2008). Taste novelty induces intracellular redistribution of NR2A and NR2B subunits of NMDA receptor in the insular cortex. Brain Res. 1215, 116-122. doi: 10.1016/j.brainres.2008.03.032

Odriozola, P., Uddin, L., Lynch, C., Kochalka, J., Chen, T., and Menon, V. (2016). Insula response and connectivity during social and non-social attention in children with autism. Soc. Cogn. Affect. Neurosci. 11, 433-444. doi: $10.1093 /$ scan/nsv126

Ogawa, H., Hasegawa, K., Otawa, S., and Ikeda, I. (1998). GABAergic inhibition and modifications of taste responses in the cortical taste area in rats. Neurosci. Res. 32, 85-95. doi: 10.1016/S0168-0102(98)00071-6

Ogawa, H., Ito, S., and Nomura, T. (1985). Two distinct projection areas from tongue nerves in the frontal operculum of macaque monkeys as revealed with evoked potential mapping. Neurosci. Res. 2, 447-459. doi: 10.1016/0168-0102(85)90017-3

Okuno, H. (2011). Regulation and function of immediate-early genes in the brain: beyond neuronal activity markers. Neurosci. Res. 69, 175-186. doi: 10.1016/j.neures.2010.12.007

Okuno, H., Akashi, K., Ishii, Y., Yagishita-Kyo, N., Suzuki, K., Nonaka, M., et al. (2012). Inverse synaptic tagging of inactive synapses via synamic interaction of Arc/Arg3.1 with CaMKIIß. Cell 149, 886-898. doi: 10.1016/j.cell.2012. 02.062

Osorio-Gomez, D., Guzman-Ramos, K., and Bermudez-Rattoni, F. (2016). Memory trace reactivation and behavioral response during retrieval are differentially modulated by amygdalar glutamate receptors activity: interaction between amygdala and insular cortex. Learn. Mem. 24, 14-23. doi: $10.1101 / \mathrm{lm} .042895 .116$
Page, G., Khidir, F., Pain, S., Barrier, L., Fauconneau, B., Guillard, O., et al. (2006). Group I metabotropic glutamate receptors activate the p70S6 kinase via both mammalian target of rapamycin (mTOR) and extracellular signal-regulated kinase (ERK1/2) signal pathways in rat striatal and hippocampal synaptoneurosomes. Neuroschem. Int. 49, 413-421. doi: 10.1016/j.neuint.2006.01.020

Pais-Vieira, C., Wing, E., and Cabeza, R. (2016). The influence of self-awareness on emotional memory formation: an fMRI study. Soc. Cogn. Affect. Neurosci. 11, 580-592. doi: 10.1093/scan/nsv141

Park, C., Gong, R., Stuart, J., and Tang, S. (2006). Molecular network and chromosomal clustering of genes involved in synaptic plasticity in the hippocampus. J. Biol. Chem. 281, 30195-30211. doi: 10.1074/jbc.M605876200

Park, S., Park, J., Kim, S., Kim, J., Shepherd, J., Smith-Hicks, C., et al. (2008). Elongation factor 2 and fragile $\mathrm{X}$ metnal retardation protein control the dynamic translation of Arc/Agr3.1 essential for mGluR-LTD. Nueron 59, 70-83. doi: 10.1016/j.neuron.2008.05.023

Parkes, S., De la Cruz, V., Bermudez-Rattoni, F., Coutureau, E., and Ferreira, G. (2014). Differential role of insular cortex muscarinic and NMDA receptors in one-trial appetitive taste learning. Neurobiol. Learn. Mem. 116, 112-116. doi: 10.1016/j.nlm.2014.09.008

Pavlov, I. (1927). Conditioned reflexes: an investigation of the physiological activity of the cerebral cortex. Ann. Neurosci. 17, 136-141.

Pearce, J., and Hall, G. (1980). A model for Pavlovian learning: variations in the effectiveness of conditioned but not of unconditioned stimuli. Psychol. Rev. 87, 532-552. doi: 10.1037/0033-295X.87.6.532

Pende, M., Um, S., Mieulet, V., Sticker, M., Goss, V., Mestan, J., et al. (2004). S6K1(-/-)/S6K2(-/-) mice exhibit perinatal lethality and rapamycin-sensitive 5 '-terminal oligopyrimidine mRNA translation and reveal a mitogen-activated protein kinase-dependent S6 kinase pathway. Mol. Cell. Biol. 24, 3112-3124. doi: 10.1128/MCB.24.8.3112-3124.2004

Penfield, W., and Faulk, M. (1955). The insula; further observations on its function. Brain 78, 445-470. doi: 10.1093/brain/78.4.445

Penfield, W., and Rasmussen, T. (1950). The Cerebral Cortex of Man. A Clinical Study of Localization of Function. New York, NY: MacMillan.

Peng, Y., Gillis-Smith, S., Jin, H., Trankner, D., Ryba, N., and Zuker, C. (2015). Sweet and bitter taste in the brain of awake behaving animals. Nature 527, 512-515. doi: 10.1038/nature15763

Pepeu, G., and Giovannini, M. (2004). Changes in acetylcholine extracellular levels during cognitive processes. Learn. Mem. 11, 21-27. doi: 10.1101/lm.68104

Perez, I., Villavicencio, M., Simon, S., and Gutiérrez, R. (2013). Speed and accuracy of taste identification and palatability: impact of learning, reward expectancy, and consummatory licking. Am. J. Physiol. Regul. Integr. Comp. Physiol. 305, R252-R270. doi: 10.1152/ajpregu.00492.2012

Philippi, C., Feinstein, J., Khalsa, S., Damasio, A., Tranel, D., Landini, G., et al. (2012). Preserved self-awareness following extensive bilateral brain damage to the insula, anterior cingulate, and medial prefrontal cortices. PLOS ONE 7:e38413. doi: 10.1371/journal.pone.0038413

Piette, C., Baez-Santiago, M., Reid, E., Katz, D., and Moran, A. (2012). Inactivation of basolateral amygdala specifically eliminates palatability-related information in cortical sensory responses. J. Neurosci. 32, 9981-9991. doi: 10.1523/JNEUROSCI.0669-12.2012

Pittenger, C., Huang, Y., Paltzki, R., Boutchouladze, R., Scanlin, H., Vronskaya, S., et al. (2000). Reversible inhibition of CREB/ATF transcription factors in region CA1 of the dorsal hippocampus disrupts hippocampus-dependent spatial memory. Neuron 34, 447-462. doi: 10.1016/S0896-6273(02)00684-0

Plath, N., Ohana, O., Dammermann, B., Errington, M., Schmitz, D., Gross, C., et al. (2006). Arc/Arg3.1 is essential for the consolidation of synaptic plasticity and memories. Neuron 52, 437-444. doi: 10.1016/j.neuron.2006.08.024

Potvin, S., and Marchand, S. (2008). Hypoalgesia in schizophrenia is independent of antipsychotic drugs: a systematic quantitative review of experimental studies. Pain 138, 70-78. doi: 10.1016/j.pain.2007.11.007

Pritchard, T., Macaluso, D., and Eslinger, P. (1999). Taste perception in patients with insular cortex lesions. Behav. Neurosci. 113, 663-671. doi: 10.1037/0735-7044.113.4.663

Qiu, Z., Zhang, M., Liu, Y., Guo, Y., Zhao, H., Song, Q., et al. (2014). GluA1 phosphorylation contributes to postynaptic amplification of neuropathic pain in the insular cortex. J. Neurosci. 34, 13505-13515. doi: 10.1523/JNEUROSCI.1431-14.2014 
Quirk, G., and Mueller, D. (2008). Neural mechanisms of extinction learning and retrieval. Neuropsychopharma 33, 56-72. doi: 10.1038/sj.npp.1301555

Rajasethupathy, P., Ferenczi, E., and Deisseroth, K. (2016). Targeting neural circuits. Cell 165, 524-534. doi: 10.1016/j.cell.2016.03.047

Ramirez-Lugo, L., Peñas-Rincón, A., Angeles-Duran, S., and Sotres-Bayon, F. (2016). Choice behavior guided by learned, but not innate, taste aversion recruits the orbitofrontal cortex. J. Neurosci. 36, 10574-10583. doi: 10.1523/JNEUROSCI.0796-16.2016

Ramirez-Lugo, L., Zaval-Vega, S., Pedroza-Llinas, R., Nunez-Jaramillo, L., and Bermudez-Rattoni, F. (2015). Effects of glutamate and its metabotropic receptors class 1 antagonist in appetitive taste memory formation. Behav. Brain Res. 284, 213-217. doi: 10.1016/j.bbr.2015.02.020

Rappaport, A., Jacob, E., Sharma, V., Inberg, S., Elkobi, A., Ounallah-Saad, H., et al. (2015). Expression of quinone reductase-2 in the cortex is a muscarinic acetylcholine receptor-dependent memory consolidation constraint. J. Neurosci. 35, 15568-15581. doi: 10.1523/JNEUROSCI.1170-15.2015

Rasmusson, D. (1993). Cholinergic modulation of sensory information. Prog. Brain Res. 98:357. doi: 10.1016/S0079-6123(08)62419-X

Rattiner, L., Davis, M., French, C., and Ressler, K. (2004). Brain-derived neurotrophic factor and tyrosine kinase receptor $B$ involvement in amygdala-dependent fear conditioning. J. Neurosci. 24, 4796-4806. doi: 10.1523/JNEUROSCI.5654-03.2004

Reil, J. (1809). Die sylvische Grube. Arch. Physiol. 9, 195-208.

Reilly, S. (1999). The parabranchial nucleus and conditioned taste aversion. Brain Res. Bull. 48, 239-254. doi: 10.1016/S0361-9230(98)00173-7

Reilly, S., and Trifunovic, R. (2001). Lateral parabranchial nucleus lesions in the rat: Neophobia and conditioned taste aversion. Brain Res. Bull. 55, 359-366. doi: 10.1016/S0361-9230(01)00517-2

Rescorla, R., and Heth, C. (1975). Reinstatement of fear to an extinguished conditioned stimulus. J. Exp. Psychol. Anim. Behav. Process. 1, 88-96. doi: 10.1037/0097-7403.1.1.88

Rescorla, R., and Wagner, A. (1972). "A theory of Pavlovian conditioning: variations in the effectiveness of reinforcement and nonreinforcement," in Classical Conditioning II: Current Research and Theory, eds A. Black and W. Prokasy (New York, NY: Appleton-Century-Crofts), 64-99.

Riley, C., and King, M. (2013). Differential effects of electrical stimulation of the central amygdala and lateral hypothalamus on $\mathrm{c}$-fos-immunoreactive neurons in the gustatory brainstem and taste reactivity behaviors in coscious rats. Chem. Senses 38, 705-717. doi: 10.1093/chemse/bjt039

Rodriguez-Duran, L., and Escobar, M. (2014). NMDA receptor activation and PKC but not PKA lead to the modification of the long-term potentiation in the insular cortex induced by conditioned taste aversion: differential role of kinases in metaplasticity. Behav. Brain Res. 266, 58-62. doi: 10.1016/j.bbr.2014. 02.049

Rodriguez-Duran, L., Castillo, D., Moguel-Gonzalez, M., and Escobar, M. (2011). Conditioned taste aversion modifies persistently the subsequent induction of neocortical long-term potentiation in vivo. Neurobiol. Learn. Mem. 95, 519-526. doi: 10.1016/j.nlm.2011.03.003

Rodriguez-Duran, L., Martinez-Moreno, A., and Escobar, M. (2017). Bidirectional modulation of taste aversion extinction by insular cortex LTP and LTD. Neurobiol. Learn. Mem. 142(Pt A), 85-90. doi: 10.1016/j.nlm.2016.12.014

Rodriguez-Garcia, G., and Miranda, M. (2016). Opposing role of cholinergic and GABAergic activity in the insular cortex and nucleus Basalis Magnocellularis during novel recognition and familiar taste memory retrieval. J. Neurosci. 36, 1879-1889. doi: 10.1523/JNEUROSCI.2340-15.2016

Rodriguez-Serrano, L., Ramirez-Leon, B., Rodriguez-Duran, L., and Escobar, M. (2014). Acute infusion of brain-derived neurotrophic factor in the insular cortex promotes conditioned taste aversion extinction. Neurobiol. Learn. Mem. 116, 139-144. doi: 10.1016/j.nlm.2014.10.007

Rolls, E. (1989). Information processing in the taste system of primates. J Exp. Biol. $146,141-164$.

Rolls, E. (2005). Taste, olfactory, and food texture processing in the brain, and the control of food intake. Physiol. Behav. 85, 45-56. doi: 10.1016/j.physbeh.2005.04.012

Rolls, E. (2015). Functions of the anterior insula in taste, autonomic, and related functions. Brain Cogn. 110, 4-19. doi: 10.1016/j.bandc.2015.07.002

Rondard, P., Goudet, C., Kniazeff, J., Pin, J., and Prezau, L. (2011). The complexity of their activation mechanism opens new possibilities for the modulation of mGlu and GABAB class $C$ G protein-coupled receptors. Neuropharmacology 60, 82-92. doi: 10.1016/j.neuropharm.2010. 08.009

Rosas, J., and Bouton, M. (1997). Renewal of a conditioned taste aversion upon return to the conditioning context after extinction in another one. Learn. Motiv. 28, 216-229. doi: 10.1006/lmot.1996.0960

Rosas, J., and Bouton, M. (1998). Context change and retention interval can have additive, rather than interactive, effects after taste aversion extinction. Psychon. Bull. Rev. 5, 79-83. doi: 10.3758/BF03209459

Rosenberg, T., Elkobi, A., Dieterich, D., and Rosenblum, K. (2016a). NMDARdependent proteasome activity in the gustatory cortex is necessary for conditioned taste aversion. Neurobiol. Learn. Mem. 130, 7-16. doi: 10.1016/j.nlm.2016.01.002

Rosenberg, T., Elkobi, A., and Rosenblum, K. (2016b). mAChR-dependent decrease in proteasome activity in the gustatory cortex is necessary for novel taste learning. Neurobiol. Learn. Mem. 135, 115-124. doi: 10.1016/j.nlm.2016.07.029

Rosenblum, K. (2008). “Conditioned taste aversion and taste learning: molecular mechanisms," in Concise Learning and Memory: The Editors Selection, ed J. Byrne (Amsterdam: Academic Press, Elsevier), 465-479.

Rosenblum, K., Berman, D., Hazvi, S., and Dudai, Y. (1996). Carbachol mimics effects of sensory input on tyrosine phosphorylation in cortex. Neuroreport 7, 1401-1404. doi: 10.1097/00001756-199605310-00015

Rosenblum, K., Futter, M., Jones, M., Hulme, E., and Bliss, T. (2000). ERKI/II regualtion by the muscarinic acetylcholine receptors in neurons. J. Neurosci. 20, 977-985.

Rosenblum, K., Futter, M., Voss, K., Erent, M., Skehel, P., French, P., et al. (2002). The role of extracellular regulated kinases I/II in late-phase long-term potentiation. J. Neurosci. 22, 5432-5441.

Rosenblum, K., Meiri, N., and Dudai, Y. (1993). Taste memory: the role of protein synthesis in gustatory cortex. Behav. Neural Biol. 59, 49-56. doi: 10.1016/0163-1047(93)91145-D

Rosenblum, K., Schul, R., Meiri, N., Hadari, Y., Zick, Y., and Dudai, Y. (1995). Modulation of protein tyrosine phosphorylation in rat insular cortex after conditioned taste aversion. Proc. Natl. Acad. Sci. U.S.A. 92, 1157-1161. doi: 10.1073/pnas.92.4.1157

Rotella, F., Olsson, K., Vig, V., Yenko, I., Pagirsky, J., Kohen, I., et al. (2015). Muscarinic and nicotinic cholinergic receptor antagonists differentially mediate acquisition of fructose-conditioned flavor preference nad quinineconditioned flavor avoidance in rats. Neurobiol. Learn. Mem. 123, 239-249. doi: 10.1016/j.nlm.2015.07.004

Roth, B. (2016). DREADDs for neuroscientists. Neuron 89, 683-694. doi: 10.1016/j.neuron.2016.01.040

Royet, J., and Plailly, J. (2004). Lateralization of olfactory processes. Chem. Senses 29, 731-745. doi: 10.1093/chemse/bjh067

Rudy, J., and O'Reilly, R. (1999). Contextual fear conditioning, conjuctive representations, pattern completion and the hippocampus. Behav. Neurosci. 113, 867-880. doi: 10.1037/0735-7044.113.5.867

Sadacca, B., Rothwax, J., and Katz, D. (2012). Sodium concentration coding gives way to evaluative coding in cortex and amygdala. J. Neurosci. 32, 9999-10011. doi: 10.1523/JNEUROSCI.6059-11.2012

Saddoris, M., Holland, P., and Gallagher, M. (2009). Associatively learned representation of taste outcomes activate taste-encoding neural ensembles in gustatory cortex. J. Neurosci. 29, 15386-15396. doi: 10.1523/JNEUROSCI.3233-09.2009

Sakata, K., Martinowich, K., Woo, N., Schloesser, R., Jimenez, D., Ji, Y., et al. (2013). Role of activity-dependent BDNF expression in hippocampalprefrontal cortical regulation of behavioral perseverance. Proc. Natl. Acad. Sci. U.S.A. 110, 15103-15108. doi: 10.1073/pnas.1222872110

Samuelsen, C., Gardner, M., and Fontanini, A. (2012). Effects of cuetriggered expectation on cortical processing of taste. Neuron 74, 410-422. doi: 10.1016/j.neuron.2012.02.031

Samuelsen, C., Gardner, M., and Fontanini, A. (2013). Thalamic contribution to cortical processing of taste and expectation. J. Neurosci. 33, 1815-1827. doi: 10.1523/JNEUROSCI.4026-12.2013

Sano, Y., Shobe, J., Zhou, M., Huang, S., Shuman, T., Cai, D., et al. (2014). CREB regulates memory allocation in the insular cortex. Curr. Biol. 24, 2833-2837. doi: $10.1016 /$ j.cub.2014.10.018 
Saper, C. (1982). Convergence of autonomic and limbic connections in the insular cortex of the rat. J. Comp. Neurol. 210, 163-173. doi: 10.1002/cne.902100207

Sarter, M., and Bruno, J. (1997). Cognitive functions of cortical acetylcholine: toward a unifying hypothesis. Brain Res. Brain Res. Rev. 23, 28-46. doi: 10.1016/S0165-0173(96)00009-4

Schier, L., Blonde, G., and Spector, A. (2016). Bilateral lesions in a specific subregion of posterior insular cortex impair conditioned taste aversion expression in rats. J. Comp. Neurol. 524, 54-73. doi: 10.1002/cne.23822

Schier, L., Hashimoto, K., Bales, M., Blonde, G., and Spector, A. (2014). Highresolution lesion-mapping strategy links a hot spot in rat insular cortex with impaired expression of taste aversion learning. Proc. Natl. Acad. Sci. U.S.A. 111, 1162-1167. doi: 10.1073/pnas.1315624111

Schultz, W. (2010). Dopamine signals for reward value and risk: basic and recent data. Behav. Brain Funct. 6:24. doi: 10.1186/1744-9081-6-24

Seeley, W., Menon, V., Schatzberg, A., Keller, J., Glover, G., Kenna, H., et al. (2007). Dissociable intrinsic connectivity networks for salience processing and executive control. J. Neurosci. 27, 2349-2356. doi: 10.1523/JNEUROSCI.5587-06.2007

Senn, V., Wolff, S., Herry, C., Grenier, F., Ehrlich, I., Grundermann, J., et al. (2014). Long-range connectivity defines behavioral specificity of amygdala neurons. Neuron 81, 428-237. doi: 10.1016/j.neuron.2013.11.006

Shelley, B., and Trimble, M. (2004). The insular lobe of Reil - its anatomicofunctional behavioural and neuropsychiatric attributes in humans - a review. World J. Biol. Psychiatry 5, 176-200. doi: 10.1080/15622970410029933

Sheng, M., McFadden, G., and Greenberg, M. (1990). Membrane depolarization and calcium induce c-fos transcription via phosphorylation of transcription factor CREB. Neuron 4, 571-582. doi: 10.1016/0896-6273(90)90115-V

Shura, R., Hurley, R., and Taber, K. (2014). Insular cortex: structural and functional neuroanatomy. J. Neuropsychiatry Clin. Neurosci. 26, 276-282. doi: 10.1176/appi.neuropsych.260401

Singh, M., Giles, L., and Nasrallah, H. (2006). Pain insensitivity in schizophrenia: trait or state marker? J. Psychiatr. Prac. 12, 90-102. doi: 10.1097/00131746-200603000-00004

Slouzkey, I., Rosenblum, K., and Maroun, M. (2013). Memory of conditioned taste aversion is erased by inhibition of PI3K in the Insular Cortex. Neuropsychopharmacology 38, 1143-1153. doi: 10.1038/npp.2013.20

Small, D., Gregory, M., Mak, Y., Gitelman, D., Msulam, M., and Parrish, T. (2003). Dissociation of neural representation of intensity and affective valuation in human gustation. Neuron 39, 701-711. doi: 10.1016/S0896-6273(03)00467-7

Spector, A. (1995). Gustatory parabranchial lesions disrupt tasteduided quinine responsiveness in rats. Behav. Neurosci. 109, 79-90. doi: 10.1037/0735-7044.109.1.79

Spector, A. (2015). Behavioral analyses of taste function and ingestion in rodent models. Physiol. Behav. 152, 516-526. doi: 10.1016/j.physbeh.2015. 04.026

Spector, A., and Glendinning, J. (2009). Linking peripheral taste processes to behavior. Curr. Opin. Neurobiol. 19, 370-377. doi: 10.1016/j.conb.2009.07.014

Spence, C. (2015). Multisensory flavor perception. Cell 161, 24-35. doi: 10.1016/j.cell.2015.03.007

Staiger, J., Masanneck, C., Bisler, S., Schleicher, A., Zuschratter, W., and Zilles, K. (2002). Excitatory and inhibitory neurons express c-Fos in barrel-related columns after exploration of a novel environment. Neuroscience 109, 687-699. doi: 10.1016/S0306-4522(01)00501-2

Stapleton, J., Lavine, M., Wolpert, R., Nicolelis, M., and Simon, S. (2006). Rapid taste responses in the gustatory cortex during licking. J. Neurosci. 26, 4126-4138. doi: 10.1523/JNEUROSCI.0092-06.2006

Stephane, M., Kuskowski, M., McClannahan, K., Sureru, S. C., and Nelson, K. (2010). Evaluation of speech misattribution bias in schizophrenia. Psychol. Med. 40, 741-748. doi: 10.1017/S003329170999081X

Steward, O., and Shuman, E. (2003). Compartmentalized synthesis and degradation of proteins in neurons. Neuron 40, 347-359. doi: 10.1016/S0896-6273(03)00635-4

Stone, M., Maffei, A., and Fontanini, A. (2011). Amygdala stimulation evokes timevarying synaptic responses in the gustatory cortex in anesthetised rats. Front. Integr. Neurosci. 5:3. doi: 10.3389/fnint.2011.00003

Swan, J., and Pearce, J. (1988). The orienting response as an index of stimulus associability in rats. J. Exp. Psychol. Anim. Behav. Process. 14, 292-301. doi: 10.1037/0097-7403.14.3.292
Swank, M. (2000). Phosphorylation of MAP kinase and CREB in mouse cortex and amygdala during taste aversion learning. Neuroreport 11, 1625-1630. doi: 10.1097/00001756-200006050-00006

Swank, M., and Sweatt, J. (2001). Increased histone acetyltransferase and lysine acetyltransferase activity and biphasic activation of the ERK/RSK cascade in insular cortex during novel taste learning. J. Neurosci. 21, 3383-3391.

Sweatt, J. (2001). The neuronal MAP kinase cascade: a biochemical signal integration system subserving synaptic plasticity and memory. J. Neurochem. 76, 1-10. doi: 10.1046/j.1471-4159.2001.00054.x

Taha, S., Nicola, S., and Fields, H. (2007). Cue-evoked encoding of movement planning and execution in the rat nucleus accumbens. J. Physiol. 584(Pt 3), 801-818. doi: 10.1113/jphysiol.2007.140236

Teber, I., Kohling, R., Speckmann, E., Barnekow, A., and Kremerskothen, J. (2004). Muscarinic acetylcholine receptor stimulation induces expression of the activity-regulated cytoskeleton-associated gene (ARC). Brain Res. Mol. Brain Res. 121, 131-136. doi: 10.1016/j.molbrainres.2003.11.017

Thiels, E., Kanterewicz, B., Norman, E., Trzaskos, J., and Klann, E. (2002). Longterm depression in the adult hippocampus in vivo involves activation of extracellular signal-regualted kinase and phosphorylation of Elk-1. J. Neurosci. 22, 2054-2062.

Thomas, G., and Huganir, R. (2004). MAPK cascade signalling and synaptic plasticity. Nat. Rev. Neurosci. 5, 173-183. doi: 10.1038/nrn1346

Tokita, K., Armstrong, W., St John, S., and Boughter, J. J. (2014). Activation of lateral hypothalamus-projecting parabranchial neurons by intraorally delivered gustatory stimuli. Front. Neural Circuits 8:86. doi: 10.3389/fncir.2014.00086

Treisman, R. (1995). Journey to the surface of the cell: fos regulation and the SRE. EMBO J. 14, 4905-4913.

Tu, J., Xiao, B., Naisbitt, S., Yuan, J., Petralia, R., Brakeman, P., et al. (1999). Coupling of mGluR/Homer and PSD-95 complexes by the Shank family of postsynaptic density proteins. Neuron 23, 583-592. doi: 10.1016/S0896-6273(00)80810-7

Tu, J., Xiao, B., Yuan, J., Lanahan, A., Leoffert, K., Li, M., et al. (1998). Homer binds a novel proline-rich motif and links group 1 metabotropic glutamate receptors with IP3 receptors. Neuron 21, 717-726. doi: 10.1016/S0896-6273(00)80589-9

Turrigiano, G. (2012). Homeostatic synaptic plasticity: local and global mechanisms for stabilizing neuronal function. Cold Spring Harbor Persp. Biol. 4:a005736. doi: 10.1101/cshperspect.a005736

Tzingounis, A., and Nicoll, R. (2006). Arc/Arg3.1: linking gene expression to synaptic plasticity and memory. Neuron 52, 403-407. doi: 10.1016/j.neuron.2006.10.016

Vincis, R., and Fontanini, A. (2016). Associative learning changes cross-modal representations in the gustatory cortex. Elife 5:e16420. doi: 10.7554/eLife. 16420

Vitureira, N., Letellier, M., and Goda, Y. (2012). Homeostatic synaptic plasticity: from single synapses to neural circuits. Curr. Opin. Neurobiol. 22, 516-521. doi: 10.1016/i.conb.2011.09.006

Waltereit, R., Dammermann, B., Wulff, P., Scafidi, J., Staubli, U., Kauselmann, G., et al. (2001). Arg3.1/Arc mRNA induction by $\mathrm{Ca} 2+$ and cAMP requires protein kinase A and mitogen-activated protein kinase/extracellular regulated kinase activation. J. Neurosci. 21, 5484-5493.

Welzl, H., Alessandri, B., and Battig, K. (1990). The formation of a new gustatory memory trace in rats is prevented by the noncompetitive NMDA antagonist ketamine. Psychobiology 18, 43-47.

Whitney, G., and Harder, D. (1986). Phenylthiocarbamide (PTC) preference among laboratory mice: understanding of a previously "unreplicated" report. Behav. Genet. 16, 605-610. doi: 10.1007/BF01066287

Wibrand, K., Messaoudi, E., Havik, B., Steenslid, V., Lovlie, R., Steen, V., et al. (2006). Identification of genes co-upregulated with Arc during BDNF-induced long-term potentiation in adult rat dentate gyrus in vivo. Eur. J. Neurosci. 23, 1501-1511. doi: 10.1111/j.1460-9568.2006.04687.x

Wiebking, C., Duncan, N., Tiret, B., Hayes, D., Marjanska, M., Doyon, J., et al. (2014). GABA in the insula - a predictor of the neural response to interoceptive awareness. Neuroimage 86, 10-18. doi: 10.1016/j.neuroimage.2013.04.042

Willner, J., Gallagher, M., Graham, P., and Crooks, G. J. (1992). N-methyl-Daspartate antagonist D-APV selectively disrupts taste-potentiated odor aversion learning. Behav. Neurosci. 106, 312-323. doi: 10.1037/0735-7044.106.2.315

Wilson, G., Biesan, O., Remus, J., and Mickley, G. (2011). Baclofen alters gustatory discimination capabilities and induces a conditioned taste aversion (CTA). BMC Res. Notes, 4:527. doi: 10.1186/1756-0500-4-527 
Wood, P., and Richard, J. (1982). GABAergic regulation of the substantia innominata-cortical cholinergic pathway. Neuropharmacology 21, 969-972. doi: 10.1016/0028-3908(82)90108-3

Wu, K., Len, G., McAuliffe, G., Ma, C., Tai, J., Xu, F., et al. (2004). Brain-derived neurotrophic factor acutely enhances tyrosine phosphorylation of the AMPA receptor subunit GluR1 via NMDA receptor-dependent mechanisms. Mol. Brain Res. 130, 178-186. doi: 10.1016/j.molbrainres.2004.07.019

Wu, N., Wan, G. F., Jin, Z., Zhang, Z., Wang, L., Zhang, C., et al. (2017). Effects of $\mathrm{GABAB}$ receptors in the insula on recognition memory observed with intellicage. Behav. Brain Funct. 13:7. doi: 10.1186/s12993-017-0125-4

Xiao, B., Tu, J., Petralia, R., Yuan, J., Doan, A., Breder, C., et al. (1998). Homer regulates the association of group 1 metabotropic glutamate receptors with multivalent complexes of homer-related, synaptic proteins. Neuron 21, 707-716. doi: 10.1016/S0896-6273(00)80588-7

Xin, J., Ma, L., Zhang, T., Yu, H., Wang, Y., Kong, L., et al. (2014). Involvement of BDNF signaling transmission from basolateral amygdala to infralimbic prefrontal cortex in conditioned taste aversion extinction. J. Neurosci. 34, 7302-7313. doi: 10.1523/JNEUROSCI.5030-13.2014

Yamamoto, K., Koyanagi, Y., Koshikawa, N., and Kobayashi, M. (2010). Postsynaptic cell type-dependent cholinergic regulation of GABAergic synaptic transmission in rat insular cortex. J. Neurophysiol. 104, 1933-1945. doi: 10.1152/jn.00438.2010

Yamamoto, T. (2006). Neural substrates for the processing of cognitive and affective aspects of taste in the brain. Arch. Histol. Cytol. 69, 243-255. doi: $10.1679 /$ aohc.69.243

Yamamoto, T. (2008). Central mechanisms of role of taste in reward and eating. Act. Physiol. Hung. 95, 165-186. doi: 10.1556/APhysiol.95.2008.2.2

Yamamoto, T., Fujimoto, Y., Shimura, T., and Sakai, N. (1995). Conditioned taste aversion in rats with excitotoxic brain lesions. Neurosci. Res. 22, 31-49. doi: 10.1016/0168-0102(95)00875-T

Yamamoto, T., Yuyama, N., and Kawamura, Y. (1981). Cortical neurons responding to tactile, thermal and taste stimulation of the rat's tongue. Brain Res. 221, 202-206. doi: 10.1016/0006-8993(81)91075-1

Yamamoto, T., Yuyama, N., Kato, T., and Kawamura, Y. (1984). Gustatory responses of cortical neurons in rats. I. Response characteristics. J. Neurophysiol. 51, 616-635.

Yamamoto, Y. N., Kato, T., and Kawamura, Y. (1985). Gustatory responses of cortical neurons in rats. II. Information processing of taste quality. J. Neurophysiol. 53, 1356-1369.

Yarmolinsky, D., Zuker, C., and Ryba, N. (2014). Common sense about taste: from mammals to insects. Cell 139, 234-244. doi: 10.1016/j.cell.2009.10.001

Yasoshima, Y., Morimoto, T., and Yamamoto, T. (2000). Different disruptive effects on the acquisition and expression of conditioned taste aversion by blockades of amygdalar ionotropic and metabotropic glutamatergic receptor subtypes in rats. Brain Res. 869, 15-24. doi: 10.1016/S0006-8993(00)02397-0

Yasoshima, Y., Sako, N., Sinba, E., and Yamamoto, T. (2006a). Acute suppression, but not chronic genetic deficiency, of $\mathrm{c}$-fos gene expression impairs long-term memory in aversive taste learning. Proc. Natl. Acad. Sci. U.S.A. 103, 7106-7111. doi: 10.1073/pnas.0600869103

Yasoshima, Y., Scott, T., and Yamamoto, T. (2006b). Memory-dependent c-Fos expression in the nucleus accumbens and extended amygdala following the expression of a conditioned taste aversive in the rat. Neuroscience 141, 35-45. doi: 10.1016/j.neuroscience.2006.03.019

Yefet, K., Merhav, M., Kuulmann-Vander, S., Elkobi, A., Belelovsky, K., Jacobson-Pick, S., et al. (2006). Differential signal transduction cascades are activated simultaneously in the rat insular cortex and hippocampus following novel taste learning. Eur. J. Neurosci. 24, 1434-1442. doi: 10.1111/j.1460-9568.2006.05009.x

Ying, S.-W., Futter, M., Rosenblum, K., Webber, M., Hunt, S., Bliss, T., et al. (2002). Brain-derived neurotrophic factor induces long-term potentiation in intact adult hippocampus: requirement for ERK activation couple to CREB and Upregulation of Arc synthesis. J. Neurosci. 22, 1532-1540.

Young, E., and Williams, C. (2013). Differential activate on of amygdala Arc expression by positive and negatively valenced emotional learning conditions. Front. Behav. Neurosci. 7:191. doi: 10.3389/fnbeh.2013. 00191

Zaborsky, I., Helmer, I., Eckenstein, F., and Leranth, C. (1986). GABAergic input to cholinergic forebrain neurons: an ultrastructural study using retrograde tracing of HRP and double immunolabeling. J. Comp. Neurol. 250, 282-295. doi: $10.1002 / \mathrm{cne} .902500303$

Zajonc, R. (1980). Feeling and thinking: preferences need no inferences. Am. Psychol. 35, 151-175. doi: 10.1037/0003-066X.35.2.151

Zellner, M., and Ranaldi, R. (2010). How conditioned stimuli acquire the ability to activate VTA dopamine cells: a proposed neurobiological component of reward-related learning. Neurosci. Biobehav. Rev. 34, 769-780. doi: 10.1016/j.neubiorev.2009.11.011

Zhang, Y., Hoon, M., Chandrashekar, J., Mueller, K., Cook, B., Wu, D., et al. (2003). Coding of sweet bitter, and umami tastes: different receptor cells sharing similar signaling pathways. Cell 112, 293-301. doi: 10.1016/S0092-8674(03) 00071-0

Zhou, Y., and Fuster, J. (2000). Visuo-tactile cross-modal associations in cortical somatosensory cells. Proc. Natl. Acad. Sci. U.S.A. 97, 9777-9782. doi: 10.1073 /pnas.97.17.9777

Conflict of Interest Statement: The authors declare that the research was conducted in the absence of any commercial or financial relationships that could be construed as a potential conflict of interest.

Copyright (c) 2017 Yiannakas and Rosenblum. This is an open-access article distributed under the terms of the Creative Commons Attribution License (CC BY). The use, distribution or reproduction in other forums is permitted, provided the original author(s) or licensor are credited and that the original publication in this journal is cited, in accordance with accepted academic practice. No use, distribution or reproduction is permitted which does not comply with these terms. 